\title{
Effects of Micronutrients during Pregnancy and Early Infancy on Mental and Psychomotor Development
}

\author{
Hans Verhoef ${ }^{\mathrm{a}}$, Clive E. West ${ }^{\mathrm{a}, \mathrm{b}}$, Nico Bleichrodt \\ Peter H. Dekker ${ }^{\mathrm{c}}$, and Marise P. Born ${ }^{\mathrm{d}}$ \\ ${ }^{a}$ Division of Human Nutrition, Wageningen University, Wageningen; \\ ${ }^{b}$ Department of Gastroenterology and Hepatology, University Medical Centre Nijmegen, \\ Nijmegen; 'Department of Work and Organizational Psychology, Free University, \\ Amsterdam, and ${ }^{\mathrm{d} I n s t i t u t e}$ of Psychology, Erasmus University, Rotterdam, The Netherlands
}

\section{Introduction}

Spectacular progress has been made in the last decades in the global fight against deficiencies of iodine and vitamin $\mathrm{A}$ [1]. As a result, the number of people suffering from iodine deficiency has been reduced from about 1.5 billion in 1990 to about 0.5 billion now, almost entirely due to the introduction in many countries of what has been termed 'universal salt iodization'. In addition, approximately one million child deaths may have been prevented between 1998 and 2000 by vitamin A supplementation [2]. The political and financial commitment that has allowed these achievements has been generated to a large extent by scientific studies that have shown the extent of human suffering caused by these deficiencies, and that have determined the potential health gains of interventions. Progress in eliminating deficiencies of other micronutrients, notably iron, has been much slower. About two billion people, or about one third of the human population, continue to suffer from iron deficiency.

Iron supplementation programs have been advocated for infants and preschool children, largely because of concerns of possible adverse effects of iron deficiency on mental and motor development. Similar concerns were instrumental in establishing salt iodization programs. The questions that will be addressed in this chapter concern the extent to which a shortage of iodine 
NNW052327.qxd 23/06/03 1:46 PM Page 328

Micronutrients and Mental Development

and iron during fetal and infant development impairs mental development, and the extent to which this impairment can be redressed by increasing the intake of these micronutrients. First, the stages of brain development in the fetus and infant will be addressed, followed by an assessment of the timing of vulnerable periods when the brain of the fetus and infant is at high risk of exposure to an inadequate supply of iodine or iron. Where possible, the mechanisms involved will be discussed. Then, observational and intervention studies will be reviewed that have examined the effect of deficiencies of iodine or iron on mental development.

Approximately half of the world's population may be at risk of low zinc intake [3]. Given this high prevalence, inconclusive but mounting evidence that zinc deficiency during pregnancy may possibly impair the infant's neurobehavioral development and immune function should also raise great concern [4-10]. However, because of space limitations, such effects and those of other micronutrients [11] will not be reviewed in the present report.

\section{Development of the Nervous System of the Embryo and Fetus}

Gestational age, the time scale generally used to gauge prenatal growth, is derived from the date of the onset of a women's last menstrual period before conception. This method makes the embryo or fetus about 15 days older than when age is determined from the date of conception. The first 2 weeks following conception, known as the 'germinal period', involves cell division and migration of the newly fertilized egg to where it becomes implanted in the uterine wall. At this time, the blastocyst, as it is known, consists of a spherical outer cellular layer that eventually becomes various membranes providing nutritive support for the embryo, and a second inner group of cells organized into a mass that will develop into the embryo.

The next stage of development from 2 to 8 weeks after conception, the 'embryonic period', is marked by rapid differentiation of cells to form most of the organs and systems within the body. Such differentiation is achieved by migration and production of specialized cells with distinct functions. Initially, 3 layers are formed: an inner layer or endoderm that gives rise to the lining of many internal organs; the middle layer or mesoderm that gives rise to skeleton, muscle, connective tissue and the urogenital, lymph and cardiovascular systems, and the outer layer or ectoderm that gives rise to skin, hair, nails, and, important from the point of view of this chapter, the nervous system.

At the beginning of the embryonic period, 15 days after conception, a small group of cells at one end of the ectoderm starts to grow rapidly. Such growth creates a reference point for the cephalic (head) and caudal (tail) regions of the embryo and helps to distinguish the left from the right side. The signaling for the creation of this reference point is provided by retinoic acid produced 
in the mother from retinol. If the supply of retinoic acid is not optimal, the polarization process will not be successful and will lead to congenital abnormalities or fetal death [12]. The growth also results in the development of the neural tube. At about the 4th week, rapid changes in the neural tube begin. Initially, the tube closes in the cephalic region and later in the caudal region. Failure to close in the cephalic region results in anencephaly in which the cerebral hemispheres and cortex fail to develop, resulting in a newborn that will survive only a short time. Failure of the neural tube to close in the caudal region results in spina bifida in which spinal nerves grow outside the protective vertebrae. Folic acid deficiency and perhaps deficiencies of other $\mathrm{B}$ vitamins increases the risk of the neural tube failing to close [13].

From 4 to 8 weeks, there is continued rapid development of the head and brain with an enormous increase in the nerve cells: once the neural tube is closed, such neurons also migrate extensively and make contact with one another. Thus, from 4 weeks onwards, maternal deficiency of iodine, and perhaps even of iron, can have profound effects on fetal development. Even by the 5th week, the nervous system starts to function as can be witnessed by faint irregular brain wave activity. From 4 to 11 weeks after conception, which is beyond the embryo period, the corpus callosum develops. It connects the two cerebral hemispheres together and provides a pathway from one side to the other. The absence or malfunction of this structure results in seizures and mild to moderate mental retardation, as well as impaired visual and motor coordination.

The next stage of development from 9 weeks until parturition, the 'fetal period', is marked by growth in size and the genesis of processes that assist organs and systems to function. By the end of the first trimester, behavior such as opening and closing lips, skin movements on the forehead and head turning, become more coordinated while by the end of the second trimester, brain wave patterns are nearly up to the level of that of the newborn. The growth spurt of the brain starts in the second trimester. The process of neuron proliferation that began 4 weeks after conception continues for a further 16 weeks while neuron migration continues to the end of the second trimester. In the third trimester, the cerebral hemispheres, the regions of the brain most heavily involved in complex mental processing, grow rapidly, folding and developing fissures to give them a wrinkled appearance. In addition to the neurons, there are an equal number of glial cells, which normally divide up to about 2 years of age but retain the potential to divide throughout life. There are 2 groups of glial cells: the macroglia, which include the astrocytes and the oligodendrocytes, and the smaller microglia, which act as macrophages in the brain. The astrocytes form part of the blood-brain barrier and are located close to the blood vessels while the oligodendrocytes synthesize and maintain the myelin sheath in the white matter of the brain and serve as neuronal satellite cells in the gray matter of the brain. In fact, myelin is responsible for the white color of white matter. Myelination begins 


\section{Micronutrients and Mental Development}

at about 26 weeks after fertilization but continues postpartum, peaking when the child is $14-18$ months of age. By the age of 1 year, the brain has reached approximately $70 \%$ of the adult's brain weight, and by the age of 2 years this has increased to $80 \%$ [14], whilst brain maturation probably continues through adolescence and beyond.

With respect to iron, much of our limited knowledge on its importance in brain development comes from studies on rodents and other animals. It is important to take into account, however, that rodents and humans differ in the timing of birth relative to the degree of maturation of the brain at birth [15]. Growth of the human brain is slower than that of rats, and brain development in the rat at postnatal days $12-14$ is perhaps comparable to that in human babies near term. Early programming effects may be expected to occur foremost during the perinatal and early postnatal period in rats, and over a much longer period in humans including both gestation and the first years of life.

\section{Timing of Deficiencies of Iodine and Iron in Relation to Brain Development and Functioning}

Profound changes occur during normal pregnancy and lactation both in maternal micronutrient status and the supply of micronutrients to the developing brain of the child. An assessment of these changes is helpful to identify periods during which the fetus and young infant are most likely to become exposed to a limited supply of micronutrients, and thus to single out critical phases during which micronutrient deficiency can result in impaired brain development or neurological functioning.

The fetus is dependent on the placenta for its supply of nutrients. Such nutrients traverse the placenta bound to carrier proteins, or incorporated into compounds. Postpartum, nutrients are derived from the diet with the effective supply depending on the amount of food or pharmanutrient (pharmaceutical preparation) eonsumed, the nutrient content of such food or pharmanutrient, and the bioavailability or bioefficacy of precursors of such nutrients [16]. For the infant, nutrient status depends on what comes from the mother preterm, and what is ingested postpartum from breast milk, supplementary foods or pharmanutrients. The flow of iodine and iron of interest to the fetus and infant is discussed below.

\section{Iodine}

Iodine carries out its function in the body as a part of the hormones, thyroxine $\left(\mathrm{T}_{4}\right)$ and triiodothyronine $\left(\mathrm{T}_{3}\right)$ produced by the thyroid gland (fig. 1). However, initially the fetus cannot utilize iodine directly: it is dependent on the mother for $\mathrm{T}_{4}$ but after about 18-22 weeks the fetus gradually becomes more independent of the mother as it starts to synthesize its $\mathrm{T}_{4}$ from iodine 
Micronutrients and Mental Development

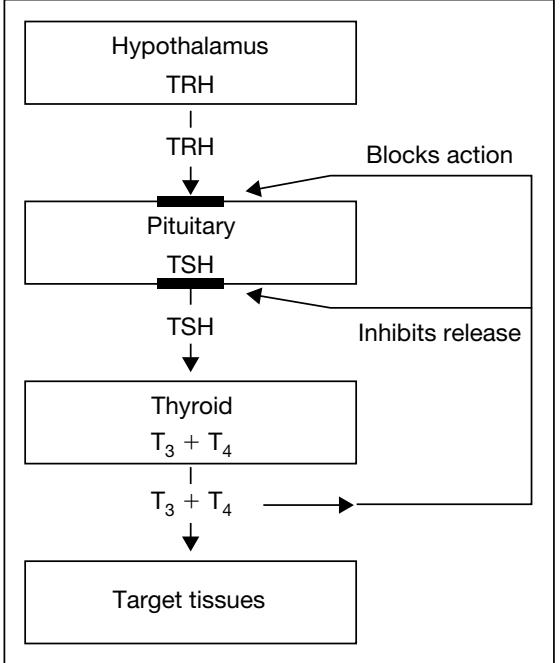

Fig. 1. Role of the thyroid gland, pituitary gland and hypothalamus in the synthesis and release of thyroid hormones. TRH $=$ Thyrotropinreleasing hormone; TSH $=$ thyroidstimulating hormone or thyrotropin; $\mathrm{T}_{3}=$ triiodothyronine; $\mathrm{T}_{4}=$ thyroxine .

supplied via the placenta [17]. This is because the thyroid and pituitary responsible for the production of $\mathrm{T}_{4}$ and thyroid-stimulating hormone respectively develop by 12 weeks, while the hypothalamus, responsible for the production of thyrotropin-releasing hormone, develops from the 10th to the 30th week. However, newborns incapable of synthesizing their own thyroid hormones due to genetic defects have cord serum $\mathrm{T}_{4}$ values of $20-50 \%$ of those of normal newborns indicating that transplacental transfer of maternal $\mathrm{T}_{4}$ continues until birth [18]. When the iodine supply to the thyroid gland is limited, the gland produces relatively more $\mathrm{T}_{3}$ than $\mathrm{T}_{4}$. When $\mathrm{T}_{4}$ levels are low, target tissues also convert $\mathrm{T}_{4}$ to $\mathrm{T}_{3}$. However, the brain can only take up $\mathrm{T}_{4}$ but not $\mathrm{T}_{3}$, so brain function is affected when $\mathrm{T}_{4}$ levels are low even though there may be sufficient $\mathrm{T}_{4}$ and $\mathrm{T}_{3}$ to carry out the function of thyroid hormones in other organs/tissues. This is particularly important for the fetus in the first half of pregnancy. If maternal $\mathrm{T}_{4}$ levels are low, the fetal brain will be exposed to low $\mathrm{T}_{4}$ levels, and this will result in brain damage.

Selenium has been found to be a component of various deiodinases thus explaining why selenium deficiency can contribute to the development of iodine deficiency disorders in areas where both iodine and selenium are deficient [see chapter by Delange]. Two deiodinases are of particular interest: type I or ID-I which is a $5^{\prime}$-deiodinase producing the normal form of $\mathrm{T}_{3}$ (lacking an iodine atom in the outer ring) and type III or ID-III which is a 5-deiodinase producing reverse $\mathrm{T}_{3}$ (lacking an iodine atom in the inner ring). From 20 weeks of gestation almost to the end of pregnancy, ID-III is active resulting in low levels of normal $\mathrm{T}_{3}$ while just prior to birth, there is a change to ID-I that produces the normal form of $\mathrm{T}_{3}$. 
NNW052327.qxd 23/06/03 1:46 PM Page 332

Micronutrients and Mental Development

Thus it appears that in iodine-deficient mothers the fetal brain has the highest risk of becoming exposed to iodine deficiency during the first half of pregnancy, and that this risk gradually declines until delivery and beyond. In addition, maternal selenium deficiency may increase the risk of brain iodine deficiency in the second half of the pregnancy. Because the brain may undergo 'critical periods' whereby iodine deficiency has differential effects in the course of its development, maternal deficiencies of iodine and selenium may produce different long-term effects despite the fact that they may both induce iodine deficiency in the fetal brain. Given differences in the geographical distributions of these deficiencies, this might explain why the syndromes related to iodine deficiency are different in various parts of the world.

\section{Iron}

Iron plays a critical role in brain development, including its postnatal stages. Youdim et al. [19], Youdim [20], Rouault [21] and Beard [22-24] reviewed the biological mechanisms whereby iron deficiency could possibly affect brain structure and functioning. The accumulation and distribution of iron in various regions of the brain depend on the stage of its development. This might indicate that brain regions vary in their vulnerability to iron deprivation, and suggests that the effect of iron deficiency on brain iron content could depend on the timing of the exposure. Animal studies indicate that low dietary intake of iron in the neonatal or preweaning period (before postnatal days 14-21) may reduce whole-brain iron content that is not reversible by dietary repletion and produce irreversible effects. In rats, such effects occur before completion of brain organization and myelination and establishment of the dopaminergic tracts. By contrast, dietary depletion in the postweaning period can also reduce brain iron content but this might be reversible upon dietary repletion. This illustrates that the timing of exposure to iron deficiency must be carefully considered when examining possible effects of iron deficiency on mental performance.

Iron is not only required for brain growth and differentiation of neuronal cells, but also for protein synthesis, hormone production and other aspects of cellular energy metabolism and functioning. When sufficiently severe to reduce hemoglobin concentrations or cause anemia, iron deficiency might adversely affect oxygen delivery, thereby leading to reduced functioning of the central nervous system. Such deleterious effects of iron deficiency might be partially or completely reversed by iron repletion.

Effects of iron deficiency might also be determined by other mechanisms. For example, it has been hypothesized that anemic children experience delayed acquisition of new skills, because they explore and interact less with their environment than nonanemic children, and they induce less stimulating behavior in their caretakers. Additionally, several studies have indicated that anemic children tend to be more fearful, withdrawn and tense, have a reduced 
ability to focus their attention [25, 26], and are therefore less exposed to environmental stimuli that may promote mental and motor development.

Iron requirements during pregnancy can be calculated on the basis of basal iron losses in non-pregnant women, iron deposition in the fetus and related tissues, and iron utilized in the expansion of hemoglobin mass [27-29]. In supplemented US women assumed to be iron-replete, the median requirements of absorbed iron over the entire pregnancy period are estimated at $250 \mathrm{mg}$ (basal losses) + 320mg (fetal and placental deposits) $+500 \mathrm{mg}$ (increase in hemoglobin mass), or $1,070 \mathrm{mg}$ [28]. Due to their smaller body size, the iron needs in iron-replete women in developing countries are probably somewhat less. However, the utilization of iron is uneven during pregnancy. Because of the absence of menstrual iron losses and the negligible needs of the fetus, iron requirements in the first trimester are very low and are probably even less than in menstruating women [30]. In addition, there are indications that erythropoiesis is less than in menstruating women, which would also suggest that iron needs are reduced [31]. The total requirements as well as the requirements for deposition in the fetus and related tissues increase markedly during the second trimester and reach their maximum during the third trimester. These demands may be increased by helminth infections. There is a broad consensus that iron demands during the second half of pregnancy may not be met by dietary sources in most developing countries, and that sufficient stores must be present at conception to avert subsequent development or exacerbation of iron deficiency at later stages of pregnancy.

These iron balance calculations implicitly assume that unconstrained erythropoiesis and maximal hemoglobin concentrations are required as an indication that all functional needs for iron have been met. This supposition has recently been questioned by Beaton [32] who argued that documented adverse health effects in mothers or infants only appear to occur at hemoglobin concentrations far below ( $<90 \mathrm{~g} / \mathrm{l}$ ) the cutoff values of $<110 \mathrm{~g} / \mathrm{l}$ as indicated by the World Health Organization or, more recently, by normal values defined the US Centers for Disease Control and Prevention [33]. Iron supplementation has a limited effect on maternal hemoglobin concentrations when the latter have reached values of $110 \mathrm{~g} / \mathrm{l}$, suggesting that these values are close to their potential and iron need is marginal [32]. The question therefore arises to what degree mild maternal iron deficiency impairs the placental transfer of iron to the fetus. This transfer, which is mediated and largely regulated by the expression of placental transferrin receptors, is generally thought to be relatively independent of maternal iron status [34-36], so that mild maternal anemia has no or little effect on iron stores in the newborn infant. Because of the high affinity of fetal hemoglobin for oxygen, the fetus 'wins' over the mother in the struggle for oxygen at the placental interface [37]. As a consequence of this high affinity, delivery of oxygen from fetal hemoglobin to tissues is lowered, and the fetus needs high hemoglobin 
NNW052327.qxd 23/06/03 1:46 PM Page 334

Micronutrients and Mental Development

concentrations to meet tissue oxygen demands. After delivery, oxygen is more readily available from the lungs, and the hemoglobin circulating at birth is in excess of what is needed. Erythropoiesis stops within days after delivery [38, 39], and elimination of red cells that have reached the end of their life span results in a dramatic drop in hemoglobin concentration in the first 2 months of life. The iron thus released is used to build up the iron stores of the infant, which are considered to be sufficient for the first 4-6 months of life.

The point of the rather long discussion in the two preceding paragraphs is to emphasize that iron deficiency has been generally considered uncommon during pregnancy and in children with normal birth weights $(>2,500 \mathrm{~g})$ until beyond 4-6 months of life (fig. 2). Exclusively breast-fed term infants are thought to rarely show any signs of iron deficiency at 6 months of age [38, 39]. Iron requirements in infants $<6$ months of age born full-term are believed to be negligible, and iron absorption low [35]. Interventions to increase iron intake in this population are therefore considered not efficacious or costeffective. Current guidelines from the International Nutritional Anemia Consultative Group, the World Health Organization and UN Children's Fund exclude children $<6$ months with birth weights $>2,500 \mathrm{~g}$ from iron supplementation programs recommended in populations at risk of iron deficiency [42, 43].

This conventional wisdom is being challenged by mounting evidence that infants in developing countries born at full-term with normal birth weight $(>2,500 \mathrm{~g})$ often have anemia when aged between 3 and 6 months, and that hemoglobin concentrations in this age range are below their potential values [42-45]. Such findings are consistent with other reports [for review see, 42] that infants with adequate birth weight but born to anemic mothers have low iron stores and are more likely to develop anemia than their counterparts born to nonanemic mothers. This issue is of great importance because conventional wisdom would imply that in children in developing countries with normal birth weights (perhaps $>80 \%$ of all live births), the period during which the brain undergoes its greatest growth spurt is believed not to coincide with exposure to iron deficiency.

McElroy et al. [45, 46] followed a large cohort of Kenyan singleton children born full-term and with normal birth weight in an area with very high malaria transmission. In each child, blood samples were collected monthly from birth onwards, and at any time when the axillary temperature was $\geq 37.5^{\circ} \mathrm{C}$. Malarial parasitemia was assessed by microscopic examination of blood slides, and a history was determined of parasitemia exposure in the 90 days preceding each hemoglobin concentration. Thus, hemoglobin concentrations in infants aged between 3 and 6 months and without documented parasitemia in the preceding 90 days were approximately $20 \mathrm{~g} / \mathrm{l}$ below values for a similarly aged reference population of healthy, well-nourished Caucasian US, Jamaican and Nigerian children (fig. 3). By contrast, the hemoglobin concentrations of these 2 groups were similar at birth and during the first 2 months of life. 
Micronutrients and Mental Development

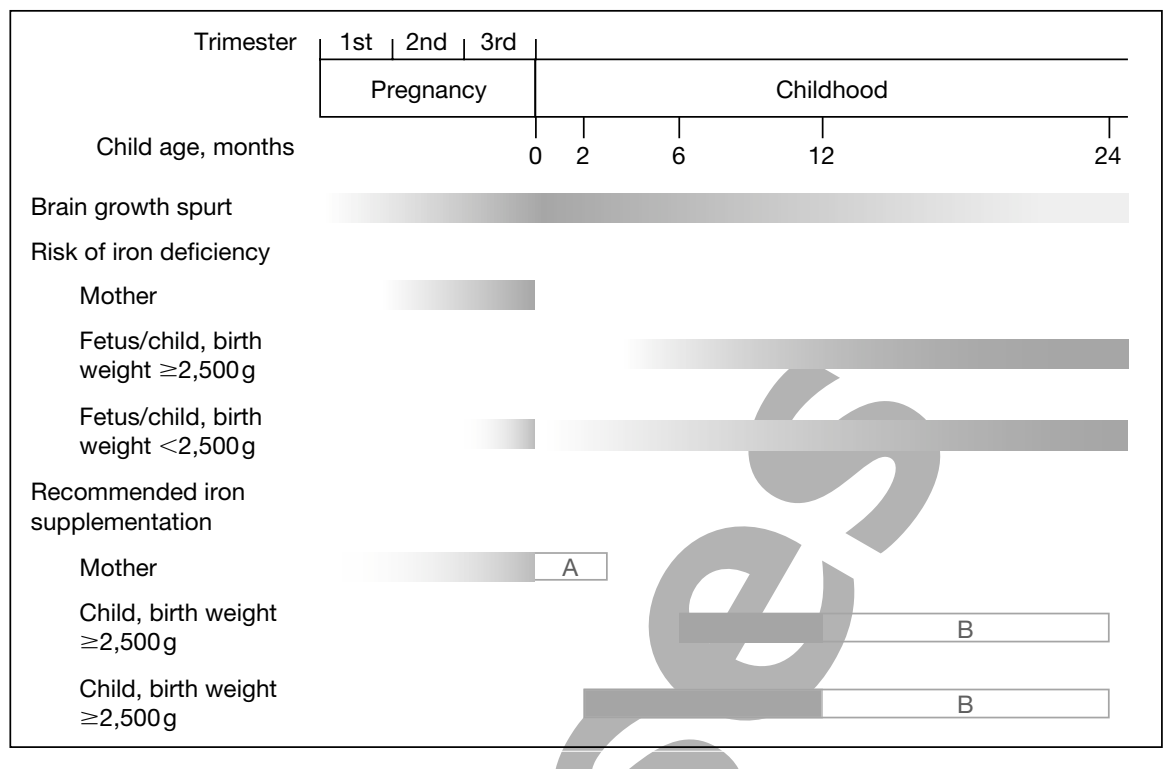

Fig. 2. Brain growth in relation to a risk of exposure to iron deficiency, and to current guidelines for iron supplementation. The growth spurt of the human brain starts in the second trimester of pregnancy and continues into the 2nd year after birth, although maturation may continue through adolescence and beyond. In pregnancy, the greatest risk of exposure to iron deficiency in the mother occurs in the second half of the gestational period, when the maximal amount of iron potentially absorbed by the intestine is insufficient to meet the demand posed by the expanding erythroid mass. It is commonly believed that, in pregnancies leading to term deliveries ( $>37$ weeks) with normal birth weight $(>2,500 \mathrm{~g})$, iron deficits leading to mild anemia in the third trimester do not substantially affect placental iron transfer to the fetus. Thus it is believed that iron deficiency does not occur in these infants during pregnancy, that iron stores in these infants at delivery are believed to be sufficient for the first 4-6 months of life, and that exclusively breast-fed term infants rarely show any signs of iron deficiency at 6 months of age. Ideally, maternal iron supplementation should start at conception (or perhaps even before), but this is not practical in most conditions. Current guidelines therefore recommend maternal iron supplementation during 6 months of pregnancy and, where $\geq 40 \%$ of pregnant women have hemoglobin concentrations $<110 \mathrm{~g} / \mathrm{l}$, supplementation should be continued to 3 months postpartum to acquire sufficient iron stores (A). The latter may not be beneficial to the newborn, because breast milk is thought to be little responsive to the iron status of the mother. In areas where iron-fortified foods are not widely and regularly consumed by young children, iron supplementation has been recommended in children with birth weights $>2,500 \mathrm{~g}$ when aged 6-12 months, and until 24 months of age where the prevalence of anemia in children aged 6-24 months exceeds $40 \%$ (B). Infants who were born premature, with low birth weight, or whose mother was severely anemic during pregnancy, have fewer iron stores at birth and develop iron deficiency at an earlier age; they therefore may need iron supplementation starting at or in some cases even before 2 months of age. See text for further explanation. 
Micronutrients and Mental Development

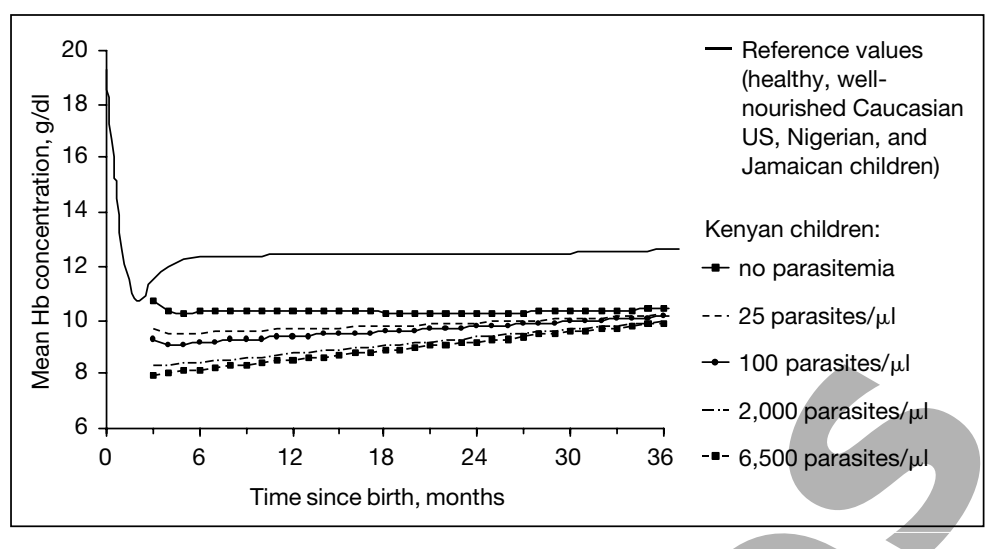

Fig. 3. Comparison of changes in hemoglobin concentrations with age between Kenyan children and reference values obtained from populations of healthy Caucasian US, Jamaican and Nigerian children [46]. Kenyan children lived in an area highly endemic for malaria and all were singleton, full-term births with normal birth weight $(>2,500 \mathrm{~g})$. Parasitemia values were calculated as geometric means of values obtained from blood samples collected during monthly surveys and at any time when febrile episodes (axillary temperature $>37.5^{\circ} \mathrm{C}$ ) occurred in the 90 days preceding measurement of hemoglobin concentrations. With permission from the American Journal of Tropical Medicine and Hygiene.

It could not be excluded, however, that decreased hemoglobin concentrations observed between 3 and 6 months of age could still reflect malaria-associated anemia, either due to effects from maternal malaria during pregnancy, or to subpatent parasitemia after birth. Nevertheless, if maternal infection would have been a major cause one would not expect these children to be born with such normal hemoglobin concentrations (Dr. Feiko ter Kuile, Centers for Disease, Control and Prevention, Atlanta, Ga., USA, personal communication). It can also not be excluded that other factors such as vitamin A deficiency may also have contributed to the low hemoglobin concentrations observed [46].

In a cross-sectional study in Indonesian infants, De Pee et al. [44] observed that $37 \%$ of those aged 3-6 months had anemia defined by a hemoglobin concentration of $<100 \mathrm{~g} / \mathrm{l}$. In those with birth weights of $>2,500 \mathrm{~g}$ and whose mothers were not anemic at the time of blood collection in their infants, this prevalence was $32 \%$, whilst maternal anemia (hemoglobin concentration $<120 \mathrm{~g} / \mathrm{l}$ ) at the time of the survey was associated with an increase in the prevalence of anemia in their infants to $45 \%$. Compared with infants in Central and West Java, the prevalence of anemia was highest in their counterparts in East Java, whereas the proportion of mothers who had received vitamin A supplements postpartum was lowest in this area. Although confounding by other factors cannot be excluded, and causality cannot be determined by cross-sectional observations, this observational evidence is 
compatible with the view that vitamin A deficiency did not substantially contribute to the anemia observed. Thus it is plausible that the hemoglobin concentration in these infants might respond to an improvement in maternal iron status during lactation or pregnancy.

In a trial in Niger, women were recruited at approximately 6 months of gestation and with hemoglobin concentrations between 80 and $120 \mathrm{~g} / \mathrm{l}$ and randomly assigned to iron supplements or placebo for the remainder of their pregnancy [47]. Compared to those receiving placebo, iron-supplemented women had marginally higher hemoglobin concentrations when measured just before delivery, and a substantially lower prevalence of iron deficiency as defined by a serum ferritin concentration of $<12 \mu \mathrm{g} /$ l. Maternal iron supplementation resulted in somewhat but statistically higher serum ferritin/concentrations in infants aged 3 months (arithmetic mean 99 versus $80 \mu \mathrm{g} / \mathrm{l}$ ). When aged 6 months, a high proportion of infants whose mothers had received placebo had low serum ferritin concentrations indicating no or marginal iron stores, whereas those whose mothers had received iron had higher values (arithmetic mean 26 versus $15 \mu \mathrm{g} / \mathrm{l}$ ). Hence, maternal iron supplementation resulted in increased iron stores in their infants aged 3-6 months. The low iron stores at 6 months of age seem unexpected, but it cannot be excluded that these are explained at least in part by the occurrence of low birth weights and the early introduction of weaning foods in the population studied. It is not possible to attribute the low serum ferritin concentrations observed to concurrent infections, because these would have resulted in increased values. It also seems unlikely that premature delivery or low birth weight could have contributed substantially to such low values.

In a cohort study in Jordan [49], pregnant women with hemoglobin concentrations either $<110 \mathrm{~g} / \mathrm{l}$ (mean $\pm \mathrm{SD} 9.9 \pm 0.7 \mathrm{~g} / \mathrm{l}$ ) or $\geq 110 \mathrm{~g} / \mathrm{l}$ at 37 weeks of gestation were recruited and followed, together with their resulting offspring. Only 4\% of children had birth weights <2,500 g. Anemic mothers had lower plasma ferritin concentrations that persisted at 6 months postpartum. When aged 6 months, infants in these 2 groups had a prevalence of iron deficiency anemia (hemoglobin concentration $<110 \mathrm{~g} / \mathrm{l}$, and plasma ferritin concentration $<12 \mu \mathrm{g} / \mathrm{l}$ or plasma zinc protoporphyrin concentration $>35 \mu \mathrm{g} / \mathrm{l}$ ) of 41 and $29 \%$, respectively, with morphological signs of red cells compatible with iron deficiency.

In a study in Honduras, Dewey et al. [50] found that 66 and $32 \%$ of exclusively breast-fed, full-term infants born to primiparous women had hemoglobin concentrations of $<110$ or $<103 \mathrm{~g} /$, respectively, whilst 17 and $22 \%$ were irondeficient (serum concentrations of ferritin $<12 \mu \mathrm{g} / \mathrm{l}$ and C-reactive protein $\leq 10 \mathrm{mg} / \mathrm{l}$ ). Similarly high prevalences of children with serum ferritin concentrations $<12 \mu \mathrm{g} / \mathrm{l}$ were observed when the analysis was restricted to infants with birth weights between 2,500 and 3,000 g; in this category, the prevalence of infants with hemoglobin concentrations $<103 \mathrm{~g} / \mathrm{l}$ was close to $50 \%$.

In the studies reviewed above, helminth infections are unlikely to have contributed substantially to iron demands in infants $<6$ months. In the 
NNW052327.qxd 23/06/03 1:46 PM Page 338

Micronutrients and Mental Development

Kenyan study, such infections were not assessed, but a subsequent survey in the same study area found that only $2.3 \%$ of infants had hookworm infection [46]. Even on the island of Zanzibar, off the Tanzanian coast, where Ascaris, Trichuris and hookworm are highly endemic as shown by high prevalence of these infections in preschool children, the prevalence of each of these infections was only $17 \%$ in children aged 4-11 months [51]. Additionally, hookworm infections in children $<30$ months had low densities, and there was no evidence that such infections were associated with decreased hemoglobin concentrations (analysis adjusted for reported fever in the week before examination, sex, and malaria parasite density).

The strength of the Kenyan study is mainly in its size, and the method of analysis which probably eliminated malaria as an important contributor to the anemia observed. An important finding from the study from Indonesia was that anemia may be common in exclusively breast-fed infants from the age of 3 months onwards. This corroborates the findings from the Kenyan study. Unfortunately, serum ferritin concentrations could not be measured in either study, so that it could not be ascertained whether the anemia observed was indeed associated with iron deficiency. The study from Niger confirmed that the low iron status observed in infants aged 6 months is due at least in part to poor iron status in the 3rd month of pregnancy and is reversible by supplementation. Unfortunately, this report provided no data on breastfeeding practices.

Despite these limitations, the evidence from these studies indicates that iron deficiency might be common, and hemoglobin concentrations reduced, in breast-fed infants aged between 3 and 6 months, born at term and with normal birth weight. If true, this would imply that iron stores at birth in these children are less than expected and that there is a need to reassess the assumption that placental iron transfer to the fetus is relatively independent of maternal iron status in pregnant women who are mildly to moderately anemic. This would also mean that these children might have been exposed to iron deficiency during the fetal stage, with adverse effects on brain development or functioning as a possible consequence. This and recent findings from rodent studies [20] that iron deficiency during the course of early brain development, both prenatally and postnatally, may irreversibly impair learning ability should raise concern.

\section{Evidence of Effects on Mental and Motor Development}

\section{Methodological Issues}

Many observational studies have shown an association between a deficiency of single nutrients, in particular iodine or iron, and poor mental and psychomotor development. However, children with one deficiency often also have deficiencies of other nutrients, or may be exposed to many other 
environmental factors such as infections or factors associated with poverty, which might also explain the associations observed. Randomized placebocontrolled trials are unique in their ability to show causal relationships between deficiency and child development. It is important to distinguish between therapeutic and preventive trials. In the former, children already exposed to deficiency are supplemented, and such trials can be efficacious only if effects were irreversible. By contrast, preventive trials are conceived to assess the efficacy of supplementation in children who have remained sufficient in the micronutrient under investigation until the start of the intervention.

With respect to iron, therapeutic effects on mental or motor development have been assessed within days or several weeks in several trials. This seems primarily based on expectations of a rapid response similar to quick recoveries in hematological indicators or behavior that may be observed following supplementation in individuals with demonstrated iron deficiency. However, the full hematological effects of iron supplementation may take longer to develop [52]. Hence, if the effects on mental or motor function were mediated by oxygen transport, then it would make more sense to assess outcomes only after several weeks or even months, as has been done in other trials [53].

Most trials with iron have been conducted in children beyond early infancy ( $>6$ months of age), presumably because younger children have been considered at no or little risk of deficiency. Evidence from trials in older children are nevertheless considered in the present report because they may give indications about possible effects in younger children if it were assumed that the effects are reversible.

No instruments are available to ascertain levels of cognition in infants, or to reliably predict intelligence or mental competence at older ages. Most studies have used either the Bayley scales of mental and motor development for infants and toddlers, Wechsler test series for preschool children (WPPSI), schoolchildren (WISC) or adults (WAIS), or the Raven Progressive Matrices test. The Bayley scales actually intend to measure the behavioral repertoire of the infant [54], which might give clues about the current state of mental development. The Wechsler test consists of 12 subtests, each measuring a different aspect of the intelligence domain. When combined into a composite score, the results give an indication of the overall intellectual capacity (IQ). The Raven test is probably the most widely used culture-reduced test, that is a test designed to produce results that are minimally influenced by the cultural context in which it is used. Its results are highly correlated with several other intelligence tests, and give a good indication of overall intelligence. In a normal population, $68 \%$ of individuals are expected to have scores within 15 points deviating from the mean value of 100 points.

Results from several studies can be weighed according to their sample size and quantitatively summarized in a meta-analysis ('analysis of analyses') 
NNW052327.qxd 23/06/03 1:46 PM Page 340

Micronutrients and Mental Development

$[55,56]$. The results are not always interpreted correctly, and we therefore briefly review the possible goals of such analyses. A meta-analysis may produce an overall summary estimate of the effect of an intervention and additionally an estimate of differences between studies. In practice, most individual trials use small sample sizes and therefore produce imprecise effect estimates [57], which may leave the impression that the findings from different studies show conflicting or at least mixed results. A meta-analysis unites data from numerous studies that on their own would have given inconclusive results [58]. Bias may still occur, of course, if individual studies have a common systematic error. Differences in results of the individual studies are also determined.

Systematic variations in effect estimates may be expected to occur, for example because of differences in the characteristics of the populations studied (e.g. differences in age or the severity of the deficiency) or the length of the follow-up period. A test for heterogeneity may be helpful to decide whether the differences observed between studies could be due to chance. If not, a search may be instigated for factors that modify the response. This may assist in identifying populations at high risk, and in which subsequent efficacy studies may be conducted. Effect sizes measured on continuous, normally distributed outcome variables may be reported as the $d$ statistic, which indicates the standardized mean difference between 2 groups. A difference in intelligence test scores of 15 points corresponds to a $d$ value of 1 standard deviation.

Meta-Analysis of Correlations with Overall Cognitive Performance

We conducted a MEDLINE search to identify observational and intervention studies that examined associations of increased intake of iodine or iron with overall cognitive performance with outcomes assessed in children aged 12 months (in 1 case, 6 months) to 15 years (in 2 cases, 20 and 45 years). This analysis was restricted to those studies that assessed effects on either a series of tests such as the Wechsler Intelligence Scale for Children (WISC), or on a specific test such as the Raven. Thus studies examining effects on psychomotor development, or focused on specific aspects of child development (e.g. play, affect, or language development) were not included.

The vast majority of the studies thus identified were not amenable to formal statistical analysis. Among a range of other limitations, many studies compared several communities rather than individuals, so that observations were dependent and additionally comprised only a few units of analysis. Most intervention studies had not used placebos or other controls. In an attempt to improve the comparability of the intervention studies, we decided to restrict our analysis to groups receiving the intervention, and to analyze test results before and after interventions as if they were independent. Similarly, in the observational studies we assumed that observations were independent. Despite or perhaps because of these drastic measures, our analysis remained severely handicapped. Studies were weighted by size, and variability between 
Micronutrients and Mental Development

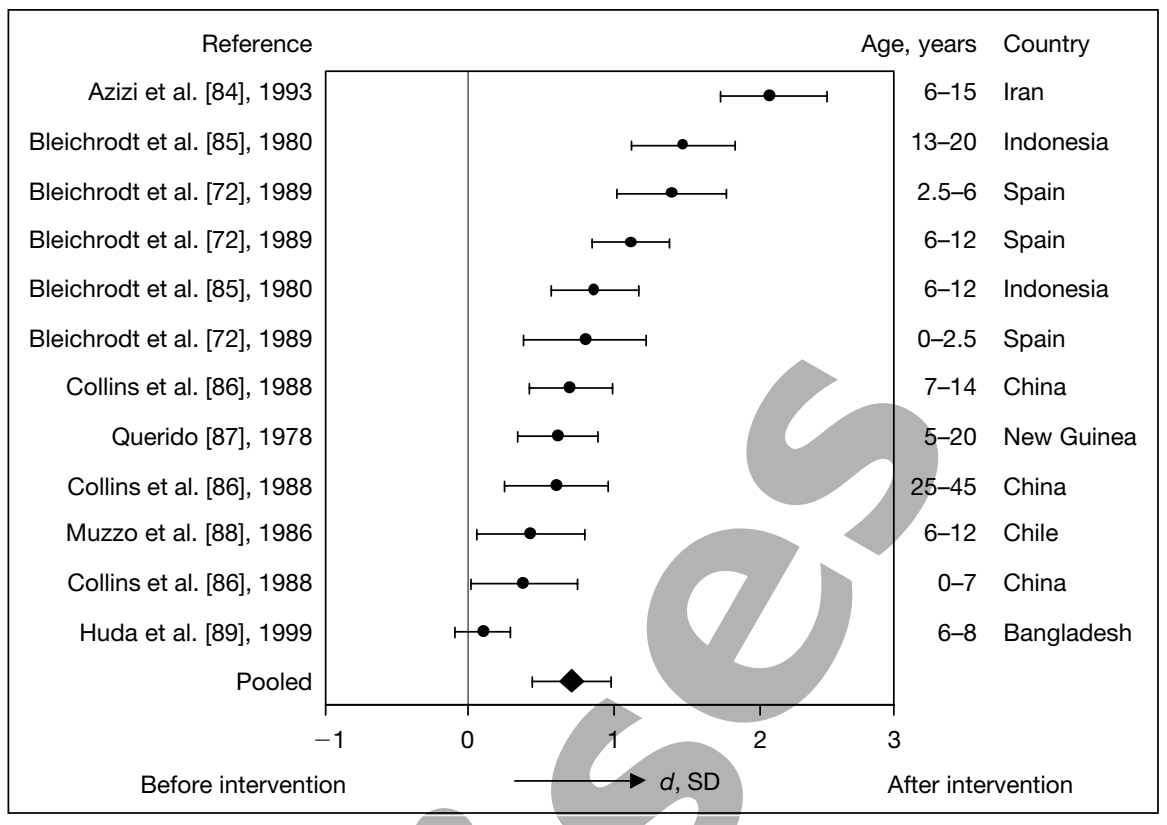

Fig. 4. Correlation of iodine deficiency with overall cognitive performance (observational study).

studies was taken into account by using a random-effects model. Thus the point estimates and corresponding confidence intervals presented below may be severely biased, the results (fig. 4-7) should therefore be interpreted with utmost caution. The individual studies seem to indicate consistently that both iodine or iron are correlated with better cognitive performance.

\section{Iodine}

From studies in New Guinea and elsewhere, it has been shown that very low levels of maternal iodine intake during pregnancy induce cretinism and that cretinism in children can be prevented by supplementation of mothers. Pharoah et al. [94] observed children in New Guinea who were born of mothers injected intramuscularly with iodized oil or saline. A total of 946 children were born, 412 to treated mothers and 534 to the saline group mothers. Seven cretins were born to the iodine-treated mothers of whom 6 were conceived prior to treatment (the time of treatment in relation to conception was not known for the 7 th), while 26 cretins were born to the untreated mothers of whom 5 were conceived prior to injection. This work clearly demonstrates that iodine deficiency is the prime cause of endemic cretinism and that it can be prevented by improving the iodine status of mothers before or early in pregnancy. With respect to studies in non-cretinous 
Micronutrients and Mental Development

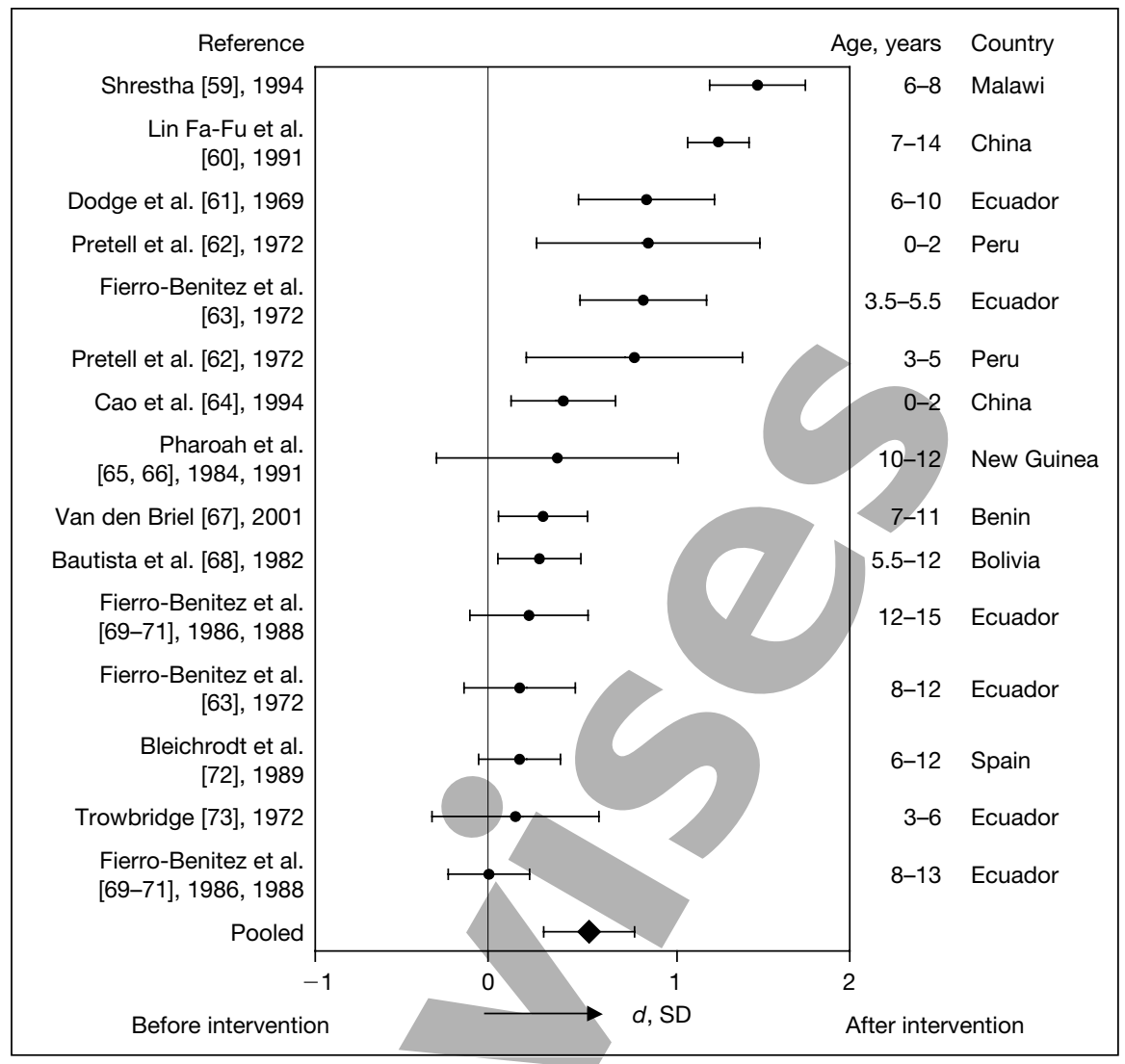

Fig. 5. Correlation of iodine therapy with overall cognitive performance (intervention study).

populations, the results observed in the meta-analyses we have carried out seemed to be consistent: the observational studies give a weighted population effect size of 0.67 (fig. 4), which corresponds to an IQ score difference of circa 10 points while for the intervention studies, an effect size was found of 0.56 (fig. 5), corresponding to an IQ score difference of 8 points.

Thus the observational studies indicate that iodine deficiency is associated with impaired cognitive development, whilst the results from the intervention studies suggest that the effects can be reversed. It would also be expected that we could obtain some insight into when iodine deficiency impairs mental and psychomotor development. However, in most of the studies, mothers were supplemented with iodine prior to conception of the children studied. Fierro-Benitz et al. [63] and Pharoah et al. [94] showed that correction of iodine deficiency after the 5th month of pregnancy did not have any beneficial effects on psychomotor development although Thilly [95] did. Thilly et al. [96] 
Micronutrients and Mental Development

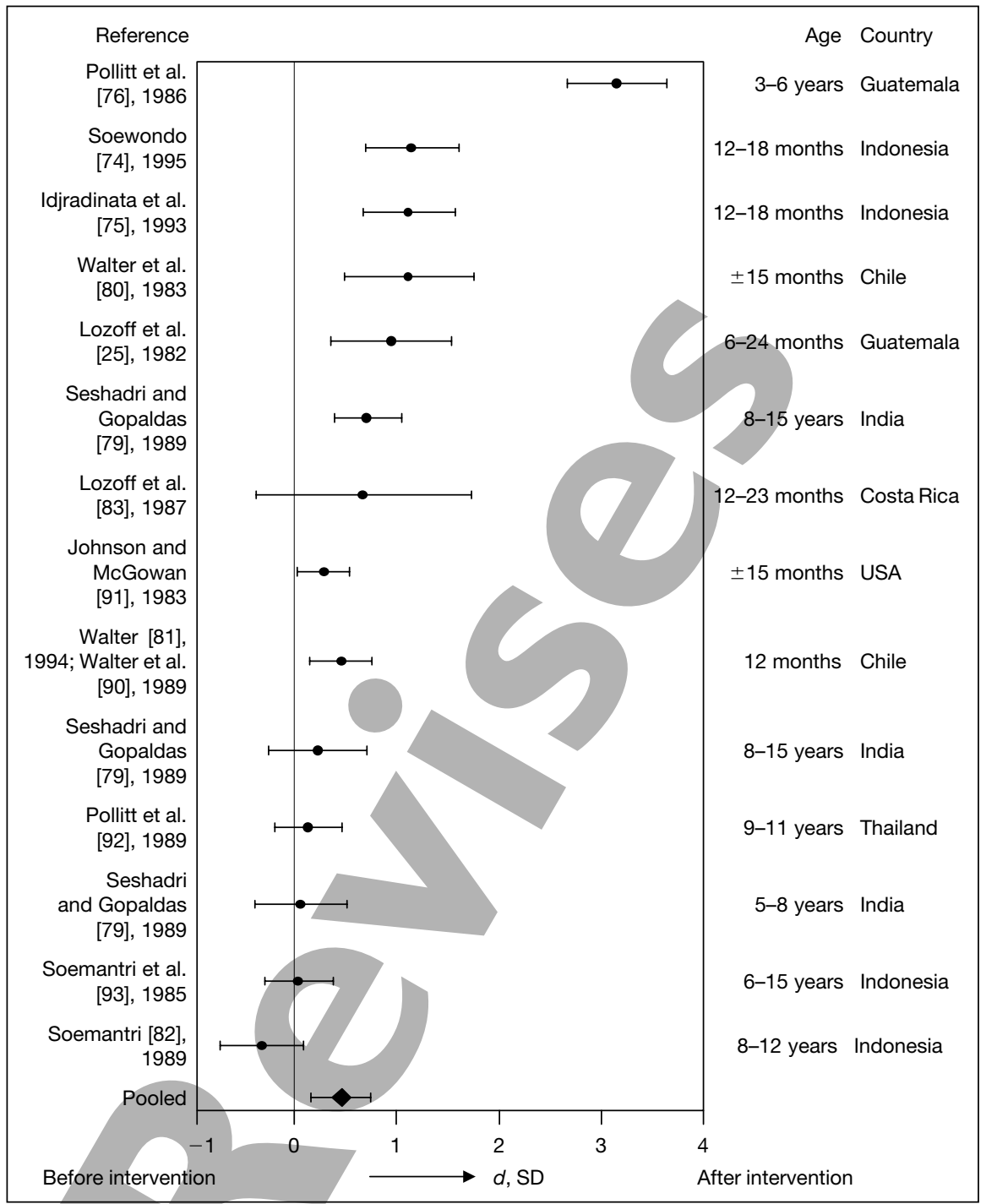

Fig. 6. Correlation of iron deficiency on overall cognitive performance (observational study).

attributed this inconsistency to other factors, particularly goitrogens in the diet. Thus, on the basis of these studies it is difficult to pinpoint at what stage of pregnancy iodine deficiency affects brain development. Both in humans and animals, transplacental transfer of maternal $\mathrm{T}_{4}$ to the fetus is crucial for the development of the central nervous system. As mentioned earlier, the fetus cannot make $\mathrm{T}_{4}$ in the first half of pregnancy when neuron proliferation 
Micronutrients and Mental Development

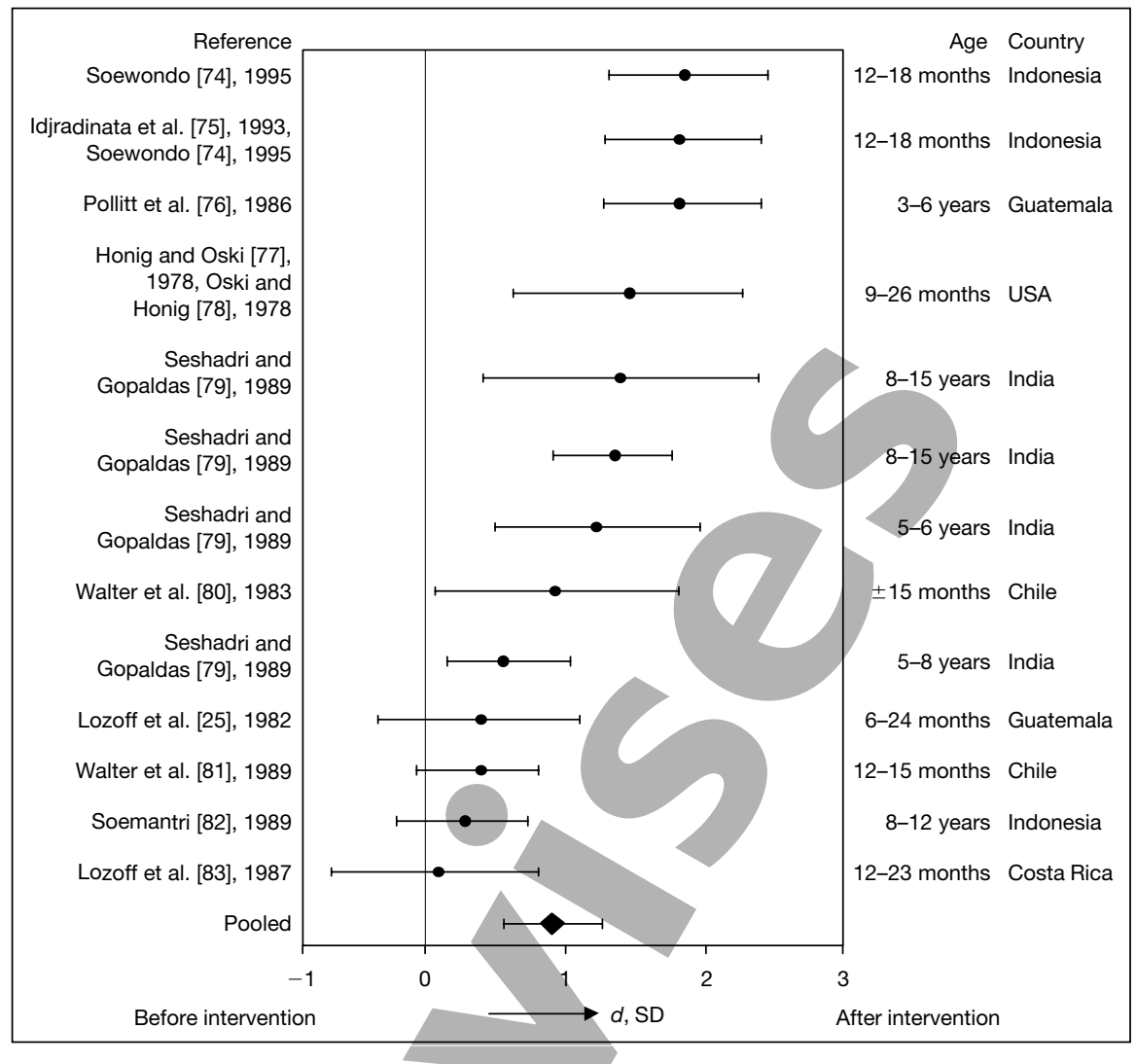

Fig. 7. Correlation of iron therapy on overall cognitive performance (intervention study).

and migration are taking place in the brain. A recent study has correlated maternal $\mathrm{T}_{4}$ concentrations during 12 weeks of pregnancy with impaired infant psychomotor performance at 10 months [97]. This indicates that a state of iodine sufficiency in the first half of pregnancy is critical for the infant, although it cannot be excluded that the fetus and newborn are also at risk during later stages of pregnancy and during lactation.

Some additional insights do come from animal studies. Injecting iodized oil into iodine-deficient sheep at 100 days of their 140-day pregnancy does restore brain growth to normal but the density of synapses in the cerebral cortex is still less than in control fetal brains [98]. This suggests that iodine deficiency in the first half of pregnancy is irreversible. A number of intervention studies have been carried out in children ranging in age from 5 to 12 years. Two studies in Bolivia [68] and Bangladesh [99] did not show any effect, while two in Malawi [59] and Benin [100] did. It may well be that the 
iodine deficiency was less severe in the populations in which no effect was found compared with those in which it was. In the study of Huda et al. [99] the subjects were euthyroid. If the effects of iodine deficiency correction on mental performance can be seen in children, this would suggest that not only is the development of the fetal nervous system involved, but also through postnatal effects of thyroid hormones. Iodine deficiency probably also affects mental performance through an effect on hearing. In Benin, hearing thresholds were shown to be associated with iodine status as measured by serum thyroglobulin concentrations, while hearing thresholds were negatively associated with performance on mental tests [101]. Studies from China have also shown that excessive intake of iodine can lead to impaired cognitive development [102].

From the description above of the studies on the relationship between iodine status and mental and psychomotor development, it can be seen that there are many unanswered questions. Although we have the methodology to address quite a few of them, it is unlikely that many additional studies will be carried out on the subject because of the widespread introduction of iodized salt. Of course, the success of this public health measure should be applauded.

\section{Iron}

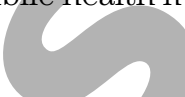

The meta-analysis of the observational studies on the correlations of iron deficiency on cognitive development indicated an effect size of 0.50 (fig. 6) corresponding to a difference in $\mathrm{IQ}$ score of circa 8 points. It is really interesting to note that the effect size for the intervention study is quite high at 0.89 (fig. 7), corresponding to an improvement in IQ of circa 13 points. It is quite probable that this 'over-correction' can be explained, at least in part by the fact that when the children were measured after the intervention, they could remember results from the initial measurement, because the period between the first and second measurement was very short.

\section{Randomized Controlled Trials}

We found 3 randomized controlled trials that assessed the effects of iron sufficiency in infants at or before the age of 6 months. In a trial among infants with birth weight $<2,500 \mathrm{~g}$, Friel et al. [103] found no difference between infants fed formula fortified with high-dose iron compared with low-dose iron (21 versus $13.4 \mathrm{mg} / \mathrm{l}$ ) in Griffith development scores or hematological indicators of iron status. However, the hemoglobin concentrations and serum ferritin concentrations reported suggest that, even in the low-dose group, few children became iron-deficient during the follow-up period. This could well explain the low efficacy observed.

A second trial was conducted among apparently healthy, bottle-fed infants aged $<2$ months from very low-income Canadian families born at or near term ( $\geq 35$ weeks of gestation) and with normal birth weight $(\geq 2,500 \mathrm{~g}$ ). These infants were identified through antenatal clinics [104]. Iron fortification of 
NNW052327.qxd 23/06/03 1:46 PM Page 346

Micronutrients and Mental Development

formula (12.8 versus $1.1 \mathrm{mg} / \mathrm{l}$ ) resulted in marginal improvements in hemoglobin concentration between 6 and 15 months of age, and marginal or mild improvements in Bayley scores for mental and motor development (maximum 6 points in psychomotor development score at 12 months of age). No or little improvement was noticed at 6 months of age. Compliance to treatment was not ascertained, and the considerable loss of children that occurred in the course of the study should raise concern about possible bias. Unfortunately, no data could be collected on maternal or infant iron status at the start of the study, so that it is difficult to extrapolate these results to other conditions.

Thirdly, in a randomized controlled trial from Niger, it was reported that infants whose mother had received iron had better iron status (see discussion above) and marginally but statistically significantly higher Apgar scores (9.6 versus 9.2) than their peers whose mothers received placebo [47]. Apgar scores are widely used as a screening test administered at delivery to newborns, and are a composite of grades given for skin color, muscle tone, breathing attempts, heart beat, and response to stimulus such as a touch or a pin prick. The scale has some use but also limitations in predicting subsequent neurologic and development impairment [105, 106]. Although the authors [47] claimed a statistically significant effect on Apgar score, their use of the $t$ test in the analysis suggests that they inappropriately assumed that this variable is continuous and normally distributed. Additionally, the scores reported in the placebo group were close to 10 , the maximum obtainable value. Thus the margin remaining for improvement may have been inadequate to measure the magnitude of improvements that may in fact have occurred ('ceiling effect') [107].

Several recent reports also reviewed the evidence from studies in older children $[51,106]$. A meta-analysis of randomized placebo-controlled trials in children aged $<3$ years [53] showed no or little effect on mental or psychomotor development within 30 days of iron therapy. Findings from longer-term treatment were inconclusive, with only one study reporting extremely large effects [75]. The number of studies that could be included in this review is small, so little can be said about variability in effects found between studies. The selective systematic review of therapeutic and preventive trials by Grantham-McGregor and Ani [108] reached similar conclusions.

Following these reviews, the findings have been published from a placebocontrolled trial among children aged 6-59 months in an area highly endemic for malaria [51]. Subgroup analysis of the results showed that iron supplementation during 12 months improved motor and language performance in children with moderate anemia (hemoglobin concentrations $<90 \mathrm{~g} / \mathrm{l}$ ).

\section{Conclusions}

There is compelling evidence that very low levels of maternal iodine intake during pregnancy induce cretinism, and that cretinism in children can be 
prevented by supplementation of mothers. There are some indications that maternal iodine deficiency may also impair cognitive performance in their offspring, and evidence that such effects during infancy impairs cognitive functioning remains inconclusive.

Adverse effects on mental and motor development of iron deficiency are plausible and could be irreversible. If so, such effects would remain manifest later in life, iron therapy would have no or little effect, and only preventive interventions might be efficacious. On the other hand, such effects may be transient and reversible by iron therapy. It is plausible that iron deficiency causes impaired cognitive performance in preterm and/or low birth weight infants but the evidence so far is inconclusive. Evidence of a high risk of exposure to iron deficiency in late pregnancy and between 2 and 6 months in infants with normal birth weights is circumstantial and has been little considered. Given also the size of this group of children, the possibility that such exposure may induce impaired cognitive and psychomotor performance should raise concerns. In view of the above, there is a need for one or several large preventive randomized placebo-controlled trials of children born at term and with normal birth weight. These trials need to be of sufficient size and duration to give conclusive evidence. Placebo-controlled trials in pregnant women are probably unethical in view of government guidelines to provide iron supplements during antenatal care.

\section{Contributions of Authors}

Hans Verhoef and Clive West drafted the sections on brain development and its timing in relation to iron and iodine nutrition, respectively. Nico Bleichrodt selected the studies for the meta-analyses, and Peter Dekker conducted the statistical analysis of these data. All authors assisted in the interpretation of the results and in the preparation of the final manuscript.

\section{References}

1 Mason JB, Lofti M, Dalmiya N, et al: The Micronutrient Report: Current Progress and Trends in the Control of Vitamin A, lodine, and Iron Deficiencies. Ottawa, The Micronutrient Initiative, 2001

2 United Nations: We the Children: End-Decade Review of the Follow-Up to the World Summit for Children. Report of the Secretary-General to the 27th Special Session of the UN General Assembly. Document/ reference number A/s-27/3. New York, United Nations, 2001.

3 Brown KH, Wuehler SE (eds): Zinc and Human Health: Results from Recent Trials and Implications for Program Interventions and Research. Ottawa, The Micronutrient Initiative, 2000.

4 Ashworth A, Morris S, Lira PI, Grantham-McGregor SM: Zinc supplementation, mental development and behaviour in low birth weight term infants in northeast Brazil. Eur J Clin Nutr 1998;52:223-227.

5 Bhatnagar S, Taneja S: Zinc and cognitive development. Br J Nutr 2001;85(suppl 2): S139-S145. 


\section{Micronutrients and Mental Development}

6 Black MM: Zinc deficiency and child development. Am J Clin Nutr 1998;68(suppl):464S-469S.

7 Hamadani JD, Fuchs GJ, Osendarp S, Huda SN, Grantham-McGregor SM: Zinc supplementation during pregnancy and effects on mental development and behaviour of infants: A follow-up study. Lancet 2002;360:290-294.

8 Salgueiro MJ, Zubillaga MB, Lysionek AE, et al: The role of zinc in the growth and development of children. Nutrition 2002;18:510-519.

9 Shah D, Sachdev HP: Effect of gestational zinc deficiency on pregnancy outcomes: Summary of observation studies and zinc supplementation trials. Br J Nutr 2001;85(suppl 2): S101-S108.

10 Black MM: The evidence linking zinc deficiency with children's cognitive and motor functioning. J Nutr 2003;133(5):1473S-1476S.

11 McArdle HJ, Ashworth CJ: Micronutrients in fetal growth and development. Br Med Bull 1999;55:499-510.

12 Durston AJ, van der Wees J, Pijnappel WW, Godsave SF: Retinoids and related signals in early development of the vertebrate central nervous system. Curr Top Dev Biol 1998;40:111-175

13 Butterworth CE Jr, Bendich A: Folic acid and the prevention of birth defects. Annu Rev Nutr 1996;16:73-97.

14 Dekaban AS: Changes in brain weights during the span of human life: Relation of brain weights to body heights and body weights. Ann Neurol 1978;4:345-356.

15 Dobbing J, Sands J: Comparative aspects of the brain growth spurt. Early Hum Dev 1979; 3:79-83.

16 West CE, Eilander A, van Lieshout M: Consequences of revised estimates of carotenoid bioefficacy for the dietary control of vitamin A deficiency in developing countries. J Nutr 2002;132:2920S-2926S

17 Morreale de Escobar G, Obregon MJ, Escobar del Rey F: Is neuropsychological development related to maternal hypothyroidism or to maternal hypothyroxinemia? J Clin Endocrinol Metab 2000;85:3975-3987.

18 Vulsma T: Transplacental transfer of thyroid hormones; in Pinchera A, Mann K, Hostalek U (eds): The Thyroid and Age. Stuttgart, Schattauer, 1998.

19 Youdim MBH, Ben-Shachar D, Yehuda S: Putative biological mechanisms of the effect of iron deficiency on brain biochemistry and behavior. Am J Clin Nutr 1989;50:607-617.

20 Youdim MBH: Nutrient deprivation and brain function: Iron. Nutrition 2000;16:504-508.

21 Rouault TA: Systemic iron metabolism: A review and implications for brain iron metabolism. Pediatr Neurol 2001;25:130-137.

22 Beard J: One person's view of iron deficiency, development, and cognitive function. Am J Clin Nutr 1995;62:709-710.

23 Beard JL: Iron biology in immune functioning, muscle metabolism and neuronal functioning. J Nutr 2001;131:568S-580S.

24 Beard J: Iron deficiency alters brain development and functioning. J Nutr 2003; 133(5):1468S-1472S

25 Lozof B, Brittenham GM, Viteri FE, Wolf AW, Urrutia JJ: The effects of short-term oral iron therapy on developmental deficits in iron-deficient anemic infants. J Pediatr $1982 ; 100 ; 3: 351-357$.

26 Lozoff B, Wolf AW, Jimenez E: Iron-deficiency anemia and infant development: Effects of extended oral iron therapy. J Pediatr 1996;129:382-389.

27 FAO/WHO: Requirements of Vitamin A, Iron, Folate, and Vitamin $\mathrm{B}_{12}$. Joint Expert Consultation Report, FAO Food and Nutrition series No. 23. Rome, Food and Agriculture Organisation of the UN, 1988.

28 Institute of Medicine: Dietary Reference Intakes for Vitamin A, Vitamin K, Arsenic, Boron, Chromium, Copper, Iodine, Iron, Manganese, Molybdenum, Nickel, Silicon, Vanadium, and Zinc. Washington, Institute of Medicine, 2002.

29 Bothwell TH: Iron requirements in pregnancy and strategies to meet them. Am J Clin Nutr 2000;72(suppl):257S-264S.

30 Hallberg L: Iron balance in pregnancy and lactation; in Fomon SJ, Zlotkin S (eds): Nutritional Anemias. Nestlé Nutrition Workshop Series. New York, Raven Press, 1992, vol 30.

31 Beguin Y, Lipscei G, Thoumsin H, Fillet G: Blunted erythropoietin production and decreased erythropoiesis in early pregnancy. Blood 1991;78:89-93. 
32 Beaton GH: Iron needs during pregnancy: Do we need to rethink our targets? Am J Clin Nutr 2000;72(suppl 1):265S-271S.

33 Centers for Disease Control and Prevention: CDC criteria for anemia in children and childbearing-age women. MMWR Morb Mortal Wkly Rep 1989;38:400-404.

34 Harris ED: New insights into placental iron transport. Nutr Rev 1992;50:329-331.

35 Sturgeon P: Studies on iron requirements in infants. III. Influence of supplemental iron during normal pregnancy on mother and infant. A: The mother. B: The infant. Br J Haematol $1959 ; 5: 31-55$.

36 Van Dijk JP: Regulatory aspects of placental iron transfer - A comparative study. Placenta 1988;9:215-226.

37 Hallberg L: Perspectives on nutritional iron deficiency. Annu Rev Nutr 2001;21:1-21.

38 Clark AC, Roche DA: Erythropoiesis in the newborn. I. Urinary erythropoietin assays. Aust Paediatr J 1973;9:121-127.

39 Halvorsen S: Plasma erythropoietin levels during the first week of life. Acta Paediatr Scand $1963 ; 52: 425$

40 Hernell O, Lönnerdal B: Iron requirements and prevalence of iron deficiency in term infants during the first 6 months of life; in Hallberg L, Asp N-G (eds): Iron Nutrition in Health and Disease. The Swedish Nutrition Foundation 20th Int Symp. London, Libbey, 1996.

41 Krebs NF: Dietary zinc and iron sources, physical growth and cognitive development of breastfed infants. J Nutr 2000;130:358S-360S.

42 Stoltzfus RJ, Dreyfuss ML: Guidelines for the Use of Iron Supplements to Prevent and Treat Iron Deficiency Anemia. International Nutritional Anemia Consultative Group/World Health Organization/UN Children's Fund. Washington, International Life Sciences Institute Press, 1998.

43 UNICEF/UNU/WHO/MI Technical Workshop: Preventing Iron Deficiency in Women and Children: Background and Consensus on Key Technical Issues and Resources for Advocacy, Planning and Implementing National Programmes, New York, October 1998. Boston, International Nutrition Foundation, 1999.

44 De Pee S, Bloem MW, Sari M, Kiess L, Yip R, Kosen S: The high prevalence of low hemoglobin concentration among Indonesian infants aged 3-5 months is related to maternal anemia. J Nutr 2002;132:2215-2221.

45 McElroy PD, Lal AA, Hawley WA, et al: Analysis of repeated hemoglobin measures in full-term, normal birth weight Kenyan children between birth and four years of age. III. The Asembo Bay Cohort Project. Am J Trop Med Hyg 1999;61:932-940.

46 McElroy PD, Ter Kuile FO, Lal AA, et al: Effect of Plasmodium falciparum parasitemia density on hemoglobin concentrations among full-term, normal birth weight children in western Kenya, IV. The Asembo Bay Cohort Project. Am J Trop Med Hyg 2000;62: 504-512.

47 Preziosi P, Prual A, Galan P, Daouda H, Boureima H, Hercberg S: Effect of iron supplementation on the iron status of pregnant women: Consequences for newborns. Am J Clin Nutr 1997:66:1178-1182.

48 Suharno D, West CE, Muhilal, Karyadi D, Hautvast JG: Supplementation with vitamin A and iron for nutritional anaemia in pregnant women in West Java, Indonesia. Lancet 1993;342:1325-1328.

49 Kilbride J, Baker TG, Parapia LA, Khoury SA, Shuqaidef SW, Jerwood D: Anaemia during pregnancy as a risk factor for iron-deficiency anaemia in infancy: A case-control study in Jordan. Int J Epidemiol 1999;28:461-468.

50 Dewey KG, Cohen RJ, Landa Rivera L, Brown KH: Effects of age of introduction of complementary foods on iron status of breast-fed infants in Honduras. Am J Clin Nutr 1998;67:878-884

51 Stoltzfus RJ, Chwaya HM, Montresor A, Albonico M, Savioli L, Tielsch JM: Malaria, hookworms and recent fever are related to anemia and iron status indicators in 0- to 5-y old Zanzibari children and these relationships change with age. J Nutr 2000;130:1724-1733.

52 Verhoef H, West CE, Nzyuko SM, et al: Intermittent administration of iron and sulfadoxinepyrimethamine to control anaemia in Kenyan children: A randomised controlled trial. Lancet 2002;360:908-914.

53 Logan S, Martins S, Gilbert R: Iron therapy for improving psychomotor development and cognitive function in children under the age of three with iron deficiency anaemia. Cochrane Database Syst Rev 2001;2:CD001444. 


\section{Micronutrients and Mental Development}

54 Pollitt E: Iron deficiency and cognitive function. Annu Rev Nutr 1993;13:521-537.

55 Hunter JE, Schmidt FL: Methods of Meta-Analysis: Correcting Error and Bias in Research Findings. Thousand Oaks, Sage Publications, 1995.

56 Rosenthal R: Meta-Analytic Procedures for Social Research. Newbury Park, Sage Publications, 1991

57 Moher D, Dulberg CS, Wells GA: Statistical power, sample size, and their reporting in randomized controlled trials. JAMA 1994:272:122-124.

58 Cooper H, Hedges LV: Research synthesis as a scientific enterprise; in Cooper H, Hedges LV (eds): The Handbook of Research Synthesis. New York, Sage, 1994, pp 3-14.

59 Shrestha RM: Effect of iodine and iron supplementation on physical, psychomotor and mental development in primary school children in Malawi; $\mathrm{PhD}$ thesis, Wageningen Agricultural University, 1994.

60 Lin FF, Ahaiti, Zhao HX, et al: The relationship of a low-iodine and high-fluoride environment to subclinical cretinism in Xinjiang. IDD Newsletter 1991;7:3.

61 Dodge PR, Palkes H, Fierro-Benitez R, Ramirez I: Effect on intelligence of iodine in oil administered to young Andean children. A preliminary report; in Stanbury JB, Kroc RL (eds): Endemic Goiter. PAHO Scientific Publication, 1969, p 193.

62 Pretell EA, Torres T, Zenteno V, Cornejo M: Prophylaxis of endemic goiter with iodized oil in rural Peru; in Stanbury JB, Kroc RL (eds): Human Development and the Thyroid Gland. Relation to Endemic Cretinism. New York, Plenum Press, 1972, p 249

63 Fierro-Benitez R, Ramirez I, Suarez J: Effect of iodine correction early in fetal life on intelligence quotient: A preliminary report; in Stanbury JB, Kroc RL (eds): Human Development and the Thyroid Gland. Relation to Endemic Cretinism. New York, Plenum Press, 1972, p 239.

64 Cao XY, Jiang XM, Dou ZH, et al: Timing of vulnerability of the brain to iodine deficiency in endemic cretinism. N Engl J Med 1994;331:1739-1744.

65 Pharoah POD, Connolly KJ: Effects of maternal iodine supplementation during pregnancy. Arch Dis Child 1991;145-147.

66 Pharoah POD, Connolly KJ, Ekins RP, Harding AG: Maternal thyroid hormone levels in pregnancy and the subsequent cognitive and motor performance of the children. Clin Endocrinol 1984;21:265-270.

67 Van den Briel T: Iodine deficiency and functional performance of schoolchildren in Benin; PhD thesis, Wageningen University, 2001.

68 Bautista A, Barker PA, Dunn JT, Sanchez M, Kaiser DL: The effects of oral iodized oil on intelligence, thyroid status, and somatic growth in school-age children from an area of endemic goiter. Am J Clin Nutr 1982;35:127-134

69 Fierro-Benitez R, Casar R, Stanburly JB, et al: Long-term effects of correction of iodine deficiency on psychomotor and intellectual development; in Dunn JT, et al. (eds): Towards the Eradication of Endemic Goiter, Cretinism and Iodine Deficiency. Washington, Pan American Health Organization, 1986, pp. 82-200.

70 Fierro-Benitez R: Iodized oil and mental development; in Medeiros-Neto G, Maciel RMB, Halpern A (eds): Iodine Deficiency Disorders and Congenital Hypothyroidism. Sao Paulo, Aché, 1986, pp 120-126.

71 Fierro-Benitez R, Cazar R, Stanbury JB, Rodriquez F, Fierro-Renoy F: Effects on schoolchildren of prophylaxis of mothers with iodized oil in an area of iodine deficiency. J Endocrinol Invest 1988;11:327-335.

72 Bleichrodt N, Escobar del Rey F, Morreale de Escobar G, Garcia I, Rubio C: Iodine deficiency, implications for mental and psychomotor development in children; in Delong GR, Robbins J, Condliffe PG (eds): Iodine and the Brain. New York, Plenum Press, 1989, pp 269-288.

73 Trowbridge FL: Intellectual assessment in primitive societies, with a preliminary report of a study of the effects of early iodine supplementation on intelligence; in Stanbury JB, Kroc RL (eds): Human Development and the Thyroid Gland. Relation to Endemic Cretinism. New York, Plenum Press, 1972, pp 137-149.

74 Soewondo S: The effect of iron deficiency and mental stimulation on Indonesian children's cognitive performance and development. Kobe J Med Sci 1995;41:1-17.

75 Idjradinata P, Pollitt E: Reversal of developmental delays in iron-deficient anaemic infants treated with iron. Lancet 1993;341:1-4.

76 Pollitt E, Saco-Pollitt C, Leibel RL, Viteri FE: Iron deficiency and behavioral development in infants and preschool children. Am J Clin Nutr 1986;43:555-565. 
77 Honig AS, Oski FA: Developmental scores of iron deficient infants and the effects of therapy. Infant Behav Dev 1978;1:68-176.

78 Oski FA, Honig AS: The effects of therapy on the developmental scores of iron-deficient infants. J Pediatr 1978;92:21-25.

79 Seshadri S, Gopaldas T: Impact of iron supplementation on cognitive functions in preschool and school-aged children: The Indian experience. Am J Clin Nutr, 1989;50:675-686.

80 Walter T, Kovalskys J, Stekel A: Effect of mild iron deficiency on infant mental development scores. J Pedriatr 1983;68:828-838.

81 Walter T, De Andraca I, Chadud P, Perales CG: Iron deficiency anemia: Adverse effects on infant psychomotor development. Pediatrics 1989;84,1:7-17.

82 Soemantri AG: Preliminary findings on iron supplementation and learning achievement of rural Indonesian children. Am J Clin Nutr 1989;50:689-702.

83 Lozoff B, Brittenham GM, Wolf AW, McClish DK, Kuhnert PM, Jimenez E, et al: Iron deficiency anemia and iron therapy effects on infant developmental test performance. Pediatrics 1987;79,6:981-195.

84 Azizi F, Sarshar A, Nafarabadi M, et al: Impairment of neuromotor and cognitive development in iodine-deficient schoolchildren with normal physical growth. Acta Endocrinol $1993 ; 129: 501-504$

85 Bleichrodt N, Drenth PJD, Querido A: Effects of iodine deficiency on mental and psychomotor abilities. Am J Phys Anthropol 1980;53:55-67.

86 Collins JK, Boyages SC, Maberly GF, et al: The effects on iodized oil and iodized salt prophylaxis on cognitive functioning in iodine deficient endemias in China. International Conference on Iodine and the Brain, Bethesda, 1988.

87 Querido A, Bleichrodt N, Djokomoeljanto R: Thyroid hormones and human mental development. Prog Brain Res 1978;48:337-346.

88 Muzzo S, Leiva L, Carrasco D: Influence of a moderate iodine deficiency upon intellectual coefficient of school-age children; in Medeiros-Neto G, Maciel RMB, Halpern A (eds): Iodine Deficiency Disorders and Congenital Hypothyroidism. Sao Paulo, Aché, 1986, pp 40-45.

89 Huda SN, Grantham-McGregor SM, Rahman KM, Tomkins A: Biochemical hypothyroidism secondary to iodine deficiency is associated with poor school achievement and cognition in Bangladeshi children. J Nutr 1999;129:980-987.

90 Walter T: Effect of iron-deficiency anaemia on cognitive skills in infancy and childhood. Baillières Clin Haematol 1994;7:815-827.

91 Johnson DL, McGowan RJ: Anemia and infant behavior. Nutr Behav 1983;1:185-192.

92 Pollitt E, Hathirat P, Kotchabhakdi NJ, Missell L, Valyasevi A: Iron deficiency and educational achievement in Thailand. Am J Clin Nutr 1989;50:687-697.

93 Soemantri AG, Pollitt E, Kim I: Iron deficiency anemia and educational achievement. Am J Clin Nutr 1985;42:1221-1228.

94 Pharoah POD, Buttfield IH, Hetzel BS: Neurological damage to the fetus resulting from severe iodine deficiency during pregnancy. Lancet 1971;i:308-310.

95 Thilly CH: Psychomotor development in regions with endemic goiter; in Hetzel BS, Smith RM (eds): Fetal Brain Disorders - Recent Approaches to the Problems of Mental Deficiency. Amsterdam, Elsevier Biomedical Press, 1981, pp 265-282.

96 Thilly $\mathrm{CH}$, Roger G, Lagasse R, et al: Fetomaternal relationship, fetal hypothyroidism, and psychomotor retardation; in Ermans AM, Mbulamoko NM, Delange F, Ahluwalia R (eds): Role of Cassava in the Etiology of Endemic Goiter and Cretinism. Ottawa, International Development Research Center, 1980, pp 111-120.

97 Pop VJ, Kuijpens JL, van Baar AL, et al: Low maternal free thyroxine concentrations during early pregnancy are associated with impaired psychomotor development in infancy. Clin Endocrinol 1999;50:149-155.

98 Hetzel BS: Iodine deficiency disorders and their eradication. Lancet 1983;ii:1126-1129.

99 Huda SN, Grantham-McGregor S, Tomkins A: Cognitive and motor function of iodinedeficient but euthyroid children in Bangladesh do not benefit from iodized poppyseed oil (Lipiodol). J Nutr 2001;131:72-77.

100 Van den Briel T, West CE, Bleichrodt N, van der Vijver FJR, Hautvast JGAJ, Ategbo EA: Improved iodine status is associated with improved mental performance of schoolchildren in Benin. Am J Clin Nutr 2000;72:1179-1185. 


\section{Micronutrients and Mental Development}

101 Van den Briel T, West CE, Hautvast JGAJ, Ategbo EA: Mild iodine deficiency is associated with elevated hearing thresholds in children in Benin. Eur J Clin Nutr 2001;55: $763-768$.

102 Zhao J: Iodine deficiency and iodine excess in Jiangsu Province, China; PhD thesis Wageningen University, 2001.

103 Friel JK, Andrews WL, Aziz K, Kwa PG, Lepage G, L'Abbe MR: A randomized trial of two levels of iron supplementation and developmental outcome in low birth weight infants. J Pediatr 2001;139:254-260.

104 Moffatt ME, Longstaffe S, Besant J, Dureski C: Prevention of iron deficiency and psychomotor decline in high-risk infants through use of iron-fortified infant formula: A randomized clinical trial. J Pediatr 1994;125:527-534.

105 Jepson HA, Talashek ML, Tichy AM: The Apgar score: Evolution, limitations, and scoring guidelines. Birth 1991;18:83-92.

106 Juretschke LJ: Apgar scoring: Its use and meaning for today's newborn. Neonatal Netw 2000;19:17-19.

107 Fairchild MW, Haas JD, Habicht J-P: Iron deficiency and behavior: Criteria for testing causality. Am J Clin Nutr 1989;50(suppl 3):566-574.

108 Grantham-McGregor S, Ani C: A review of studies on the effect of iron deficiency on cognitive development in children. J Nutr 2001;131:649S-668S.

109 Azizi F, Kalani H, Kimiagar M, et al: Physical, neuromotor and intellectual impairment in noncretinous schoolchildren with iodine deficiency. Int J Vitam Nutr Res 1995;65:199-205.

\section{Discussion}

Dr. Delange: Thank you for this very nice paper, which I am sure will result in a lot of discussion. I would like to say that I insisted very much that your topic should be on the program of this session, because I was really concerned about the methodology of evaluating mild impairment of psychomotor and mental development in infants. Deficiencies of micronutrients such as iron, iodine, zinc or protein usually occur in mild forms. One of your colleagues, Dr Bleichrodt, has produced wonderful work indicating that severe iodine deficiency results in an IQ loss of $13.5 \%$. This is a miraculous figure which is quoted widely. Now what about the consequences of mild deficiencies? As a pediatrician, I am confused when reviewing the literature on the use of tests such as the Bayley, Denver and Griffith tests. There are many tests, often adapted for local use. So I would like to see somewhere in the proceedings of this conference a discussion of the tests that we should be using when working in the field in difficult conditions. I would like to indicate one major reason why I am personnally extremely concerned by this point. As you know the big donors, when providing money for programs, want to see success. Everybody putting money into iodization programs wants to get a success story. And it certainly is a success story, some even use the word 'miracle'. Miracles are not very compatible with science I am sorry to say. You might have seen the miraculous figure of 85 million newborns saved from brain damage each year due to iodized salt. Isn't that marvelous? The point is that this miraculous figure comes from an equation which says that the number of newborns saved from brain damage and mental retardation is the birth rate in the iodinedeficient countries multiplied by the fraction of the population which has access to iodized salt. That's it. Now there are many uncertainties in this equation. You usually don't know the birth rate in most developing countries. Regarding the figure of access to iodized salt, this is generally not known because it is rarely measured at the household level. This figure is also magic, it comes from the quantity of iodized salt produced or imported into a country divided by the total population, as simple as that. It does not take into account what I have seen in so many countries, for example in Cameroon, that tons of iodized salt are produced or are imported but stored in a 
warehouse somewhere, degrading progressively, losing its iodine content and never reaching the target population. So this figure is totally unacceptable. I am absolutely excited about what you said about iron and I am sure that iron will be discussed extensively, but I really would like to see in the proceedings a proposal for an optimal, simplified and universal method for evaluating mild impairment of neuro-intellectual development. I ask this question because I am unable to provide such information. I am not sure that anybody would be able to, but I think that if somebody would be, this would be your colleague, Dr. Bleichrodt.

Dr. Beard: I would like to respond to the previous comment as well as ask several questions. Dr. Delange has asked us to generate a fairly simple feel-friendly protocol for evaluating neuronal and emotional functioning in infants, and then be able to use that as a predictor of functioning in later life. I think that that is an impossible task, and I say that because I am in fact involved in a very large project with Dr. Lozoff and others to reevaluate the developmental indexes that are the constructs of the Bayley and the Griffith scales. Now everybody who uses these will recognize that they are broad stroke evaluation tools; they lack specificity and sensitivity to particular neural developmental processes. So in light of that, the new generation of studies use very specific tests, from visual tracking tests to defined motor scales, to evoked potential studies. These are technically fairly demanding sets of tests aimed at identifying specific neural developmental processes that are potentially affected adversely by deficiencies in nutrients such as iodine, iron, protein or zinc. In our particular case it is applied to iron deficiency. So I don't see that it is possible to boil that down to a feelfriendly task. There are 40 different tests which we are presently performing in a study of infants in the Detroit metropolitan area, and it is fairly complicated. The data are going to be incredibly exciting and revealing but it is certainly not going to be feelfriendly. Concerning your second comment about what does it all mean, I think that there are two issues. There is a scientific question, which is what neural processes are involved. When people quote your figures of the number of IQ points lost in iodine deficiency, I think that this is an issue of advocacy in which you are trying to convince donor agencies that there is a potential effect. The number may not have a scientific basis, and I perfectly agree with you. It is the same with respect to iron when we argue about irreversible effects in broad strokes based primarily on the Bayley scales, things that Dr. Verhoef was talking about. What does that mean in terms of adult functioning? It does not mean anything, or else that iron-deficient children are simply delayed in development. That argument was fine up until about 2 years ago at which time the very long-term longitudinal data from Dr. Lozoff's Costa Rican studies [1] started to come out and then the Chilean studies [2, 3]. I think that Dr. Verhoef didn't have a chance to deal with those findings because they weren't really within the construct of his talk. Using auditory evoked potentials, the studies from Chile were able for the first time to identify a biologic process, in this case nerve conduction velocity, which is functioning abnormally in iron-deficient infants, and despite iron therapy. Now Drs. Walter and Lozoff and the other investigators have looked at these Chilean children 5 years later. They are no longer infants, but preschool and school-age children, and their auditory evoked potentials are still significantly slower [4]. So there is a biological construct which says this is irreversible in children who are irondeficient at 6 months of age, so that there is now biological evidence. Now the second part is what are the developmental abnormalities with the Bayley scales, the things that Dr. Verhoef was talking about, what does that mean in later life? In Costa Rica, children who had been studied in infancy were followed up more than 10 years later. Dr Lozoff and colleagues [1] were able to recapture 87\% of her original cohort of 191 infants, so it is a pretty miraculous longitudinal study. And when you look at that these children who are now late adolescents and in some cases parents themselves, they 


\section{Micronutrients and Mental Development}

have lower IQ, they have had more problems in school, there is more depression, there is more anxiety, there is a whole series of adult-functioning abnormalities in these individuals who were iron deficient in early life. So I personally am much more confident than with the Bayley scales, that it is not so much that there is a developmental delay but there is a little window into a process. It lacks specificity in sensitivity but it is telling us that in all likelihood in later life individuals will not function as well as if they would have been iron-sufficient in early life. I hope that what we will be able to tell you in 5 years which specific processes in terms of neural development are affected.

Dr. Sazawal: I want to make two comments. I think I agree with Dr. Beard in terms of the Bayley scales being broad measures. But one thing that we need to keep in mind is that the interpretation of the results of such tests in the first 2 years of life is not very easy. So if you measure effects on test scores in the first year of life or the first 2 years of life, how does that relate to what is actually picked up? The question is not whether an effect that has been measured means something, because it definitively does. However, these measurements are so insensitive at that age that the chance that you will pick up something is very minimal. So many studies that did not find a difference may have failed because there are no differences. On the other hand, it may simply be that these studies did not have the potential to detect effects in the age range studied. The second comment I have concerns the chance that you can find an effect of supplementation within 60 days. To me, this is not plausible in view of the biology of iron deficiency. It would require that iron supplementation corrects the deficiency as well as the developmental process, and this is not plausible within 60 days.

Dr. Verhoef: There are obviously problems in extrapolating results from Bayley scales measurements to impaired functioning later in life. The scores obtained with these scales are known to have a fairly low predictive value for what happens later in life. I think that we are mostly concerned about long-term irreversible effects. The only conclusive evidence about this will come from a long-term well-randomized trial that measures effects later in life. The instruments currently available can measure cognitive development at later ages but not in early childhood. Thus if we use these instruments at later ages, then we can be much more confident that it measures what we want to measure. So if we are concerned for example that iron deficiency would affect IQ later in life, then let us have a randomised controlled trial that will evaluate effects after 10 or 20 years of supplementation. I think that this would be the only type of study that would settle this issue once and for all.

Dr. Sazawal: We did a randomized controlled trial in which, as part of a factorial design, we gave iron or placebo to low birth weight children in the first 9 months of life, and we are following that cohort during school age. What we have found but have not yet published, is that, although the supplementation stopped at 9 months of age, there were measurable group differences in Bayley scores at 15 months of age.

Dr. Verhoef: But the question remains. What does it mean?

Dr. Sazawal: Exactly, the only thing that I wanted to bring up for discussion, which is different from Dr. Lozoff and colleagues. This is a unique population in which iron deficiency develops in early childhood and then regular diets keep them replete for the rest of their lives, so it is really easy to see the effects of an isolated iron deficiency in the early years of life. But in most places especially in India and most of South Asia, the story is the same. You can give a child therapeutic iron, bring him to a normal iron store at the age of one year, and the next year it is down again. So you have these processes where you have a deficiency in early infancy, a deficiency in the second year of life and then concurrent deficiency in the later parts of the life. The challenge that we are facing is that when you do these long-term randomized control trials, you have to deal with this recurrence of iron deficiency. 
Dr. Verhoef: Obviously the outcome has to be ascertained after many years. In addition, if you do a preventive trial, you should continue the intervention long enough to cover the period of risk. Thus the intervention period should cover pregnancy and perhaps the first year of life or so, and then the outcome should be evaluated many years afterwards.

Dr. Moukarzel: You showed us a recommendation for iron supplementation in infants. Are you trying to tell us to change this recommendation and, if you had to make a recommendation now, would you recommend iron therapy or supplementation between 2 and 6 months in breast-fed infants?

Dr. Verhoef: I think it is too early for that. I think the evidence is still very circumstantial and the only way to confirm that the anemia observed in this age range is indeed due to iron deficiency is by conducting randomized control trials. There are many confounders that must be excluded, for example vitamin A deficiency and hereditary conditions such as thalassemia. So I think that the only way to go forward is to conduct such randomized trials to see what can be achieved and then make recommendations on the basis of such studies.

Dr. Beard: I would not do a placebo-controlled intervention trial in infancy anymore. I am convinced by the data that exist now, the Indonesian study by Idjradinata and Pollitt [5] and perhaps Dr. Sazawal's study, when it is published, are the only studies to use a placebo anemic group in the design. All the other 14 clinical intervention trials [REFS?] that have been published have not utilized placebos, and it is intriguing that the Indonesian study is in fact the one study showing a reversibility of effects of iron therapy. But I am convinced by those other 13 studies that there are irreversible effects of iron deficiency in early life, so I am not going to take on the personal responsibility of saying I am going to include a placebo group. That may be bad science but that is a personal decision that investigators make, I am not going to run a trial like that. So that leaves you with the preventative kind of trial and I think you are raising a really good point, which is a preconception iron intervention trial or multiple micronutrient trial in which you actually get at the notion of micronutrient status in the first 8-10 weeks of pregnancy is the way to actually test your hypothesis.

Dr. Verhoef: I fully agree with that. Ideally speaking that would be the case. Iron supplementation during pregnancy is a major policy in most countries and therefore you cannot use placebo. On the other hand, we know that the compliance to iron supplementation during pregnancy is very low. This is a bad thing, of course, but on the other hand you might use it to your advantage. Thus a trial might be conducted whereby a comparison is made between children whose mothers were allocated to either supervised or unsupervised iron supplementation. I am not as convinced as you are whether it would be unethical to do iron placebo-controlled trials in infancy and later in life., Many questions remain about the possible effects of iron supplementation on infectious diseases. The study by Menendez et al. [6] has shown that iron supplementation is probably safe in infants less than 6 months of age in Tanzania or in areas of high endemic malaria. The question remains what iron supplementation would do in older children and in children in the areas of lower malaria endemicity. The reason why I bring this up is that the children studied by Dr. Menendez and colleagues [6] probably were at fairly low risk of malaria because they supplemented iron in the first half year of life in a highly endemic malaria area. These children are probably protected by maternal antibodies and giving iron would not be expected to have so much effect anyway. The question is still open whether the benefits of iron supplementation later in life in malaria areasoutweigh the risk of adverse effects. For this reason, I still think that there is a need for placebo-controlled trials to look at mortality, and the question whether iron 


\section{Micronutrients and Mental Development}

supplementation prevents impairment in cognitive development could also be studied in such a trial.

Dr. Sazawal: In the Tanzanian trial that we are doing to assess the effect of zinc supplementation on mortality, there is also a factorial whereby about 30,000 children are randomized to receive supplements with either iron or its placebo from the age of 1 month onwards. So probably within the next 1.5 years we should have data on the effects of iron supplementation on mortality. My personal view is that there is a lot of data on iron supplementation in malaria areas but that there is a big gap in our knowledge of the effect of iron supplementation on other infectious diseases in developing countries, particularly where the prevalence of such infections is very high. There are very few data from South Asia with regard to the effects of iron supplementation in settings where $40-50 \%$ of babies afer of low birth weightThese infants are basically malnourished during the first year of life, they have about 8-10 episodes of diarrhea and 1.5-2 episodes of pneumonia, and have recurrent infestation in the first 2 years of life. Now in that setting, what happens when you give a long-term high-dose iron therapy is still an open question.

Dr. Verhoef: It certainly is. Let me add that we have just published a study looking at the effects of iron supplementation in slightly older children than were studied previously in the Tanzania trial by Menendez and colleagues [6]. The best estimate is that it probably leads to a perhaps $20 \%$ increase in malaria if you use twice weekly iron supplementation. But the confidence interval, as indicated by its upper limit, is still compatible with the 3 -fold increase and that remains a big worry. I do think there is a need for a large trial that really addresses this question, not only for malaria but also for other infectious diseases.

Dr. Allen: I would like to make a couple of comments that are issues that have arisen from the studies by Dewey, Domeloff and colleagues [7, 8]. Even well-nourished iron-replete babies in Sweden during the first 4 months of age responded by increasing their hemoglobin concentration when they were supplemented with iron. Hemoglobin is not a good indicator of iron status during the first 2 months of life. Secondly, the cutoffs that are being used right now seem to be wrong for hemoglobin and probably for ferritin, and new cutoffs have been suggested for most iron status measures in infancy [7]. Thirdly, iron supplementation from 4 to 9 months produces no additional benefits at 9 months compared to iron supplementation between 6 and 9 months. Another general question is what happens to these children when we stop these supplementation trials and we let them to go back to where they were before? Nobody is going to supplement children forever, and this always bothers me.

Dr. Verhoef: It is true that there are a number of questions on how to determine iron status in the very young. I am a bit puzzled by your comment that if you give iron supplementation you get an increase in hemoglobin concentration and therefore it is not a good indicator. I fail to see the rationale for that.

Dr. Allen: This was in Swedish babies who are known to be iron-replete and getting iron-loaded formulas, and still when they were given additional iron supplements, the hemoglobin went up even more.

Dr. Verhoef: I don't understand why you infer from such data that hemoglobin is not a good indicator of anemia. To me, that doesn't necessarily seem to be indicated by the results that you quote. It might be that increasing hemoglobin concentrations when they are close to their maximum may be beneficial, but it appears to me that this is not indicated by the evidence that you refer to. I missed the second part of your question, sorry.

Dr. Allen: It was a general question on all of these studies about the ethics of supplementing and then stopping. I don't have an answer right here but we should think about it. 
Dr. Verhoef: On the other hand I question whether it is yet ethical to use iron supplementation in malaria areas. Although evidence is accumulating that it is safe, larger trials are required to settle this issue with certainty.

Dr. Zlotkin: Just in response to Dr. Allen's question on sustainability. We have just completed a relatively short-term 2-month trial of supplementing anemic infants in Ghana. The infants who responded positively to the supplementation were randomized into 4 groups, 1 was a placebo group and another group received iron, and followed these infants for the next 18 months. And what we found was that, after 2 months of adequate treatment, the majority of the infants remain nonanemic for the next 18 months. So it is possible that a relatively short period of adequate treatment will last for a relatively long period of time.

Dr. Verhoef: This also seems to be indicated by the results of the study by Menendez and colleagues [6], which showed that if you give iron between 8 and 24 weeks of age, the effects on reducing the incidence of severe anemia seem to be sustained over the entire first year of life. I presume that this indicates that iron stores are built up to some degree.

\section{References}

1 Lozoff B, Jimenez E, Hagen J, Mollen E, Wolf AW: Poorer behavioral and developmental outcome more than 10 years after treatment for iron deficiency in infancy. Pediatr 2000; 105:e51.

2 Angulo-Kinzler RM, Peirano P, Lin E, Algarin C, Garrido M, Lozoff B: Twenty-four-hour motor activity in human infants with and without iron deficiency anemia. Early Hum Dev 2002;70: $85-101$.

3 Angulo-Kinzler RM, Peirano P, Lin E, Garrido M, Lozoff B: Spontaneous motor activity in human infants with iron-deficiency anemia. Early Hum Dev 2002;66:67-79.

4 Algarin C, Peirano P, Garrido M, Pizarro F, Lozoff B: Iron deficiency anemia in infancy: longlasting effects on auditory and visual system functioning. Pediatr Res 2003;53:217-223.

5 Idjradinata P, Pollitt E: Reversal of developmental delays in iron-deficient anaemic infants treated with iron. Lancet 1993;341:1-4.

6 Menendez C, Kahigwa E, Hirt R, et al: Randomised placebo-controlled trial of iron supplementation and malaria chemoprophylaxis for prevention of severe anaemia and malaria in Tanzanian infants. Lancet 1997;350:844-850.

7 Domeloff M, Dewey KG, Lonnerdal B, Cohen RJ, Hernell O: The diagnostic criteria for iron deficiency in infants should be reevaluated. J Nutr $2002 ; 132: 3680-3686$.

8 Domeloff M, Lonnerdal B, Dewey KG, Cohen RJ, Rivera LL, Hernell O: Sex differences in iron status during infancy. Pediatrics 2002;110:545-552.

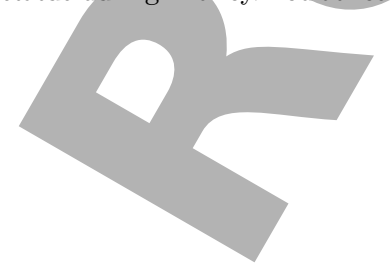




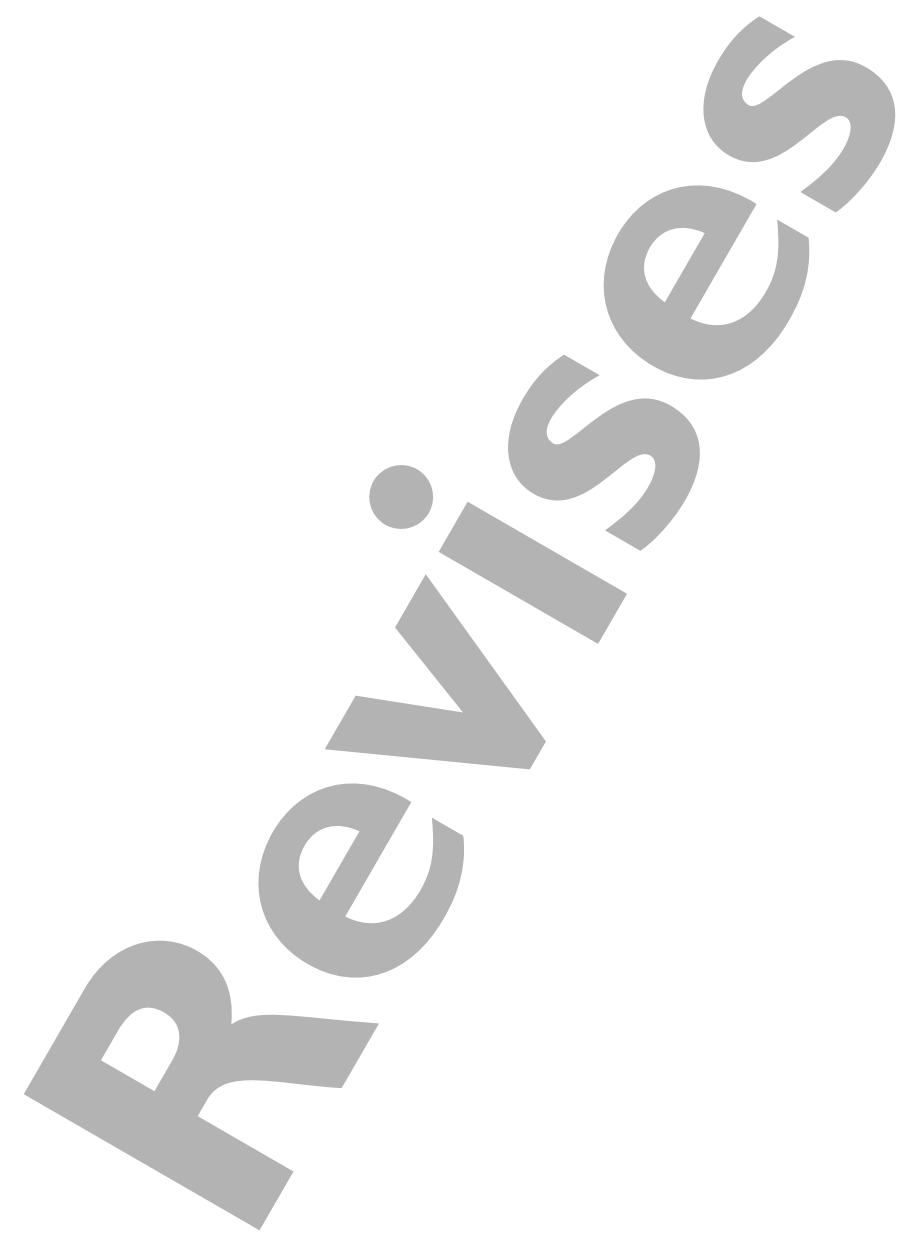

